Aus der Abteilung Mund-, Kiefer- und Gesichtschirurgie (Prof. Dr. med. Dr. med. dent. H. Schliephake) im Zentrum Zahn-, Mund- und Kieferheilkunde der Medizinischen Fakultät der Universität Göttingen

\title{
Unterkieferrekonstruktion durch kontrollierte rh-BMP-2 - Freisetzung mit Hilfe von präformierten Trägern aus Polylaktid und Kollagen
}

\author{
Inaugural-Dissertation \\ zur Erlangung des Doktorgrades \\ für Zahnheilkunde \\ der Medizinischen Fakultät \\ der Georg-August-Universität zu Göttingen \\ vorgelegt von \\ Sarah Frase geb. Lunk \\ aus Göttingen
}

Göttingen 2009 
Dekan: Prof. Dr. med. C. Frömmel

I. Berichterstatter: Prof. Dr. med. Dr. med. dent. H. Schliephake

II. Berichterstatter/in:

III. Berichterstatter/in:

Tag der mündlichen Prüfung: 
$\underline{\text { Inhaltsverzeichnis }}$

1 Einleitung 1

1.1 Knochengewebe 1

1.2 Knochenbildung (Ossifikation) 3

1.2.1 Chondrale Ossifikation 3

1.2.2 Desmale Ossifikation 4

1.3 Knochenregeneration 5

1.4 Osteokonduktion 5

1.5 Osteoinduktion 6

1.6 Knochenersatzmaterialien 6

1.7 Trägermaterialien 8

1.8 Trägerbeladung und Freisetzungskinetik 10

1.9 Wachstumsfaktoren 11

1.9.1 BMP-Historie 13

1.9.2 BMP-Rezeptoren und Signalübertragung $\quad 15$

1.9.3 rh-BMP-2 16

1.10 Zielsetzung 16

2 Material und Methoden $\quad 18$

2.1 rh-BMP-2 18

$\begin{array}{ll}2.2 \text { Polylaktidträger } & 19\end{array}$

$\begin{array}{ll}2.3 \text { Kollagenträger } & 19\end{array}$

2.4 Versuchstiere 20

2.4.1 Tierart 20

2.4.2 Haltung und Fütterung $\quad 20$

2.5 Herstellung der Implantate 21

$2.6 \mathrm{OP} 222$

2.7 Herstellung der Trenn-Dünnschliff-Präparate 23

2.8 Mikroskopie/Untersuchungsmethoden 25

2.8.1 Mikroskop 25

2.8.2 Messprogramm 26 
$\underline{\text { Inhaltsverzeichnis }}$

3 Ergebnisse 29

3.1 Polylaktidträger 29

$3.1 .196 \mu \mathrm{g}$ rh-BMP-2 29

3.1.2 $48 \mu \mathrm{g}$ rh-BMP-2 31

3.1.3 Vergleich der $96 \mu$ g- und der $48 \mu$ g-Konzentration $\quad 33$

3.2 Kollagenträger 34

3.2.196 $\mu \mathrm{g}$ rh-BMP-2 34

3.2.2 $48 \mu \mathrm{g}$ rh-BMP-2 36

3.2.3 Vergleich der $96 \mu$ g- und der $48 \mu$ g-Konzentration $\quad 38$

3.3 Vergleich der Polylaktid- und Kollagenträger 39

4 Diskussion 4

4.1 Interesse an Wachstumsfaktoren 41

4.2 Einfluss des Implantatlagers auf die Wirksamkeit der BMPs 42

4.3 Geeignete Trägermodelle 43

4.4 Polylaktid als Carrier $\quad 45$

4.5 Kollagen als Carrier 47

4.6 Vergleich der beiden Carrier 49

5 Zusammenfassung $\quad 51$

6 Anhang $\quad 53$

6.1 Vorabveröffentlichungen 53

6.2 Abkürzungsverzeichnis 54

6.3 Tabelle 3 - Ergebnisse $\quad 55$

6.4 Signifikanzen $\quad 57$

7 Literaturverzeichnis $\quad 59$ 


\section{EINLEITUNG}

Wachstumsfaktoren ermöglichen der modernen Medizin und Chirurgie neue Therapieansätze nach Tumoroperationen oder bei der Behandlung von komplizierten, schlecht heilenden Frakturen. Für die Stimulation von Knorpelund Knochenwachstum hat sich eine Gruppe von Faktoren besonders hervorgetan: die sogenannten BMPs - Bone Morphogenetic Proteins (Barnes et al. 1999, Kübler 1997, Paralkar et al. 2002). Insbesondere BMP-2 hat sich als potenter Faktor für die Induktion von Knochenneubildung erwiesen. Inzwischen kann dieser Faktor sogar synthetisch hergestellt werden (rh-BMP-2) (Ducy und Karsenty 2000). Die Frage stellt sich jedoch nach wie vor nach der geeigneten Konzentration, die eine optimale Reaktion des vorhandenen Gewebes auslöst und nach geeigneten Trägermaterialien, mittels derer man die Wachstumsfaktoren einbringen und kontrolliert freisetzen kann.

In der vorliegenden Arbeit wurden deshalb unterschiedlich hohe Konzentrationen des Wachstumsfaktors rh-BMP-2 mittels zweier Trägermaterialien (präformierte Polylaktidträger und Kollagenträger equinen Ursprungs) in experimentelle Knochendefekte eingebracht und die Auswirkungen auf die Knochenheilung und Knochenneuentstehung beobachtet.

\subsection{Knochengewebe}

Knochengewebe ist ein spezialisiertes, besonders stabiles Stützgewebe. Neben der Stützfunktion ist es für den Mineralstoffwechsel (vor allem des Kalziums) und durch das Knochenmark für die Hämatopoese (Blutbildung) zuständig. Bestandteile des Knochengewebes sind zum Einen die Zellen (Osteoblasten, Osteozyten, Osteoklasten), zum Anderen die Interzellularsubstanz, bestehend aus Grundsubstanz, kollagenen Fasern und mineralischen Anteilen (Baumhoer et al. 2000, Horn et al. 2003, (Martin TJ 1988, Moll und Moll 2003). 


\section{Die Zellen:}

- Osteoblasten entstammen mesenchymalen Vorläuferzellen. Sie bilden die Grundsubstanz des Knochens, das Osteoid. Hauptsyntheseprodukt ist dabei Typ-IKollagen. Des Weiteren werden Glykoproteine wie z.B. Osteokalzin und Osteonektin hergestellt, welche die Einlagerung von Mineralien in die Kollagenfibrillen fördern.

- Osteoklasten sind mehrkernige Riesenzellen, die aus der MonozytenMakrophagen-Linie stammen. Mit Hilfe der alkalischen Phosphatase sind sie in der Lage den Knochen enzymatisch abzubauen und Kalzium freizusetzen. Hierbei entstehen so genannte Howshipsche Lakunen, in denen die Osteoblasten liegen.

- Osteozyten sind die Nachfahren der Osteoblasten, die sich im Rahmen der Knochenbildung (Ossifikation) mit Knochen umgeben und eingemauert haben. Sie liegen in Lakunen im Knochen und kommunizieren über ihre feinen Zytoplasmaausläufer untereinander. An inneren und äußeren Knochenoberflächen finden sich besondere Osteozyten, die Bone-Lining-Cells, die die für den Knochenumbau zuständigen Zellen anlocken können (Abendroth 1992, Baumhoer et al. 2000, Dietsch 1992, Moll und Moll 2003).

\section{Interzellularsubstanz:}

Die Interzellularsubstanz oder auch Extrazelluläre Matrix besteht in ihrer Grundsubstanz aus organischen Anteilen wie Typ I Kollagenfasern, Proteoglykanen und Glykoproteinen (Osteonektin, Osteokalzin). In diese Grundsubstanz werden die mineralischen Anteile wie anorganische Phosphate, Kalzium (99\% des Körperkalziums ist im Knochen gespeichert), Karbonat, Magnesium oder Fluor eingelagert. Anorganische Phosphate und Kalzium bilden stabile Gefüge, die Apatitkristalle (v.a. Hydroxylapatit) (Baumhoer et al. 2000, Martin TJ 1988). 
Es gibt zwei Arten von Knochengeweben: Faser- bzw. Geflechtknochen und Lamellenknochen. Der embryonale Faser- und Geflechtknochen besteht aus ungeordneten kollagenen Fasersystemen und wird in den ersten Jahren in den mechanisch belastbareren Lamellenknochen umgewandelt.

Der Lamellenknochen ist auf Grund seines lamellenartigen Aufbaus stabiler als der Faserknochen. Er kann in zwei Bereiche unterteilt werden: Die Substantia compacta, kompakter, sehr stabiler Knochen, der sich meist randständig in den Röhrenknochen oder auch Kieferknochen befindet, und die Substantia spongiosa, der innere Knochenanteil, der in lockeren schwammartigen Knochenbälkchen organisiert ist. Zwischen diesen Schwämmchen befinden sich im Knochenmark die blutbildenden Zellen. Außer an den überknorpelten Gelenkenden ist jeder Knochen ringsum von einer Knochenhaut, dem Periost, überzogen, das für die Anheftung der Sehnen und Bänder an den Knochen sorgt. Das Periost enthält zahlreiche Nervenfasern (hohe Schmerzempfindlichkeit), Blut- und Lymphgefäße sowie Osteoblastenstammzellen, die bei der Frakturheilung eine wichtige Rolle spielen (Baumhoer et al. 2000, Moll und Moll 2003).

\subsection{Knochenbildung (Ossifikation)}

Bei der Knochenbildung wird zwischen zwei verschiedenen Entstehungsweisen unterschieden - der chondralen und der desmalen Ossifikation.

\subsubsection{Chondrale Ossifikation}

Die indirekte chondrale Knochenbildung erfolgt über ein knorpeliges Vorläufermodell und geschieht in zwei sich überschneidenden Schritten, der perichondralen und der enchondralen Ossifikation. 
Bei der perichondralen Ossifikation wandeln sich Zellen des Perichondriums zu Osteoblasten um und produzieren eine knöcherne Manschette um die knorpelige Diaphyse (Knochenschaft) des Knochens. Hierdurch verschlechtert sich die Versorgung der Knorpelzellen, der Chondrozyten, sie hypertrophieren, treiben blasenartig auf, die Interzellularsubstanz verkalkt und die Knochenmanschette vergrößert sich. Aus ihr entwickelt sich die spätere Kompakta.

Gleichzeitig kommt es zur enchondralen Ossifikation, indem Blutgefäße durch die perichondrale Knochenmanschette dringen und mit ihnen Mesenchymzellen und Chondroklasten, die den Knorpel von innen abbauen. Aus den Mesenchymzellen entwickeln sich Osteoblasten, die mit der Ablagerung von Osteoid und dem Aufbau von Knochen beginnen.

Die knorpeligen Epiphysen der Röhrenkochen stellen die Wachstumszentren des Knochens dar. Erst mit Verknöcherung dieser Wachstumsfugen schließt das Größenwachstum des Körpers ab. Im weiteren Verlauf des Lebens kommt es zu Umbauprozessen, mit denen sich der Knochen an die gegebenen Situationen anpasst (Remodeling) (Baumhoer et al. 2000, Moll und Moll 2003, Rakosi und Jonas 1989, Schwenzer und Ehrenfeld 2002).

\subsubsection{Desmale Ossifikation}

Die desmale Ossifikation geschieht auf bindegewebiger Grundlage. Es kommt zu einer Zellvermehrung im Mesenchym und zur Entwicklung von Osteoblasten. Diese beginnen Osteoid und Kollagen zu produzieren. Durch die Einlagerung von Mineralien wie Kalzium und Phosphat kommt es zur Ausbildung von Apatitkristallen und es entsteht ein Faser/Geflechtknochen mit zunächst noch geringer Verkalkungsdichte. Dieser wird durch vermehrte Apatiteinlagerung und funktionale Ausrichtung von Knochenbälkchen in den belastbareren Lamellenknochen des Erwachsenen umgewandelt (Moll und Moll 2003, Rakosi und Jonas 1989). 


\subsection{Knochenregeneration}

Knochen ist ein äußerst regenerationsfähiges Gewebe, das in der Lage ist sowohl bei einer Fraktur wieder auszuheilen als auch im Laufe des Lebens sich ständig verändernden mechanischen Belastungen anzupassen (Martin RB 2000, McKibbin 1978). Kommt es zu einer Knochenfraktur und dabei zu einer Verletzung der intraossären und periostalen Blutgefäße, bildet sich im Frakturspalt ein Hämatom. Zellen chondrogener und osteogener Potenz wandern ein und bilden den sogenannten Kallus, ein Knorpel-Knochengewebe, welches anschließend im Rahmen der sekundären Frakturheilung in stabilen Lamellenknochen umgewandelt wird (Remodeling) (Barnes et al.1999, Baumhoer et al. 2000).

Gelingt es die Frakturenden durch Osteosynthese zu stabilisieren, ist auch eine primäre Frakturheilung ohne Kallusbildung möglich.

Kommt es nicht zu einer knöchernen Durchbauung des Defektes, sondern wird nur eine bindegewebige Überbrückung erreicht, spricht man von einer Pseudarthrose (Littenberg et al. 1998, Baumhoer et al. 2000).

Bei größeren Defekten überbrückt man im Rahmen einer Operation den Defekt mittels verschiedenster Materialien (siehe Knochenersatzmaterialien), die eine Osteokonduktion und/oder - induktion bewirken (Berens et al. 2000, Stützle et al. 1998, Urist 1965).

\subsection{Osteokonduktion}

Bei der Osteokonduktion dient das eingebrachte Material als Knochenleitstruktur, in die das umgebende Knochengewebe einwachsen kann. Die Regeneration geht ausschließlich vom vorhandenen Knochenlager aus, das Ersatzmaterial dient lediglich als Leitschiene und wird von Knochen durchsetzt und schließlich allmählich substituiert (Burchardt 1983, Urist 1965). 


\subsection{Osteoinduktion}

Bei der Osteoinduktion dient das eingebrachte Material nicht nur als Leitschiene, sondern besitzt einen stimulierenden Effekt auf die Zellen des Lagergewebes. Pluripotente Zellen - sogenannte Osteoprogenitor-Zellen - differenzieren sich zu Osteoblasten und beginnen mit der Bildung neuen Knochengewebes (Kübler 1997). Dies ist sowohl orthotop, d.h. im Knochengewebe, als auch heterotop, d.h. außerhalb des Knochens möglich (Sampath et al. 1992, Urist 1965, Urist et al. 1979, Wang EA et al. 1988).

\subsection{Knochenersatzmaterialien}

Schon lange besteht großes Interesse daran, die Heilung von großen Knochendefekten oder komplizierten Frakturen $\mathrm{zu}$ unterstützen und $\mathrm{zu}$ beschleunigen. 1859 versuchte Ollier im Tierexperiment Knochendefekte mittels Knochentransplantaten zu sanieren. Er prägte die Begriffe ,autogen“, ,,allogen“ und ,xenogen“(Ollier 1867).

Inzwischen sind zahlreiche unterschiedliche Methoden und Knochenersatzmaterialien beschrieben worden, die in der heutigen Behandlung von Frakturen und in der Wiederherstellungschirurgie Bedeutung finden. Dabei wird zwischen Transplantaten und Implantaten unterschieden.

\section{Transplantate}

Ein Transplantat besteht aus Zellen, Geweben oder ganzen Organen.

(z.B. Herztransplantat)

Man unterscheidet dabei zwischen autogenen, allogenen und xenogenen Transplantaten. 


\section{Autogen /Autolog}

Von autogenen/autologen Transplantaten spricht man, wenn es sich um Transplantationen innerhalb desselben Individuums handelt . Ein Vorteil der autologen Transplantate ist die optimale Antigenstruktur, die keine Immunabwehrreaktion hervorruft. Nachteilig sind jedoch die oft nur begrenzte Verfügbarkeit und die Notwendigkeit einer Entnahmeoperation (Foitzik und Merten 1999, Kübler 1997, Schwenzer und Ehrenfeld 2002).

\section{$\underline{\text { Allogen }}$}

Transplantate, die von einem anderen Individuum derselben Spezies stammen, werden als allogen bezeichnet. Da das Infektionsrisiko (Hepatitis, HIV) bei einem fremden Spender nicht unerheblich ist, sind die Indikationsbestimmungen für allogene Transplantate entsprechend hoch (Hierholzer und Zilch 1980, Lord et al. 1988, Schratt und Spyra 1997). Die Wahrscheinlichkeit für eine HIV-Übertragung bei einer allogenen Knochentransplantation beträgt 1:8x10 ${ }^{6}$ (Simmonds et al. 1992). Für Hepatitis C beträgt das Risiko $1: 1-5 \times 10^{4}$ und für Hepatitis B $1: 1 \times 10^{5}$ (Gürtler 1994). Zudem ist auch bei den allogenen Transplantaten immer eine Entnahmeoperation notwendig (Rueger JM 1998).

\section{$\underline{\text { Xenogen }}$}

Handelt es sich nicht nur um ein anderes Individuum, sondern um eine ganz andere Spezies spricht man von xenogenen Transplantaten.

Beispiele für den Knochenersatz wären hier das Biooss bzw. Ceros bovinen Ursprungs, Interpore korallinen Ursprungs oder das Algipore/Algisorb, das aus Algen gewonnen wird. Die immunogene Eiweißkomponente wird dabei durch Hitzebehandlung beseitigt, um Fremdreaktionen auf das Material zu vermeiden (Foitzik und Merten 1999, Kübler 1997, Schwenzer und Ehrenfeld 2002). 


\section{Implantatmaterialien}

Implantate bestehen aus künstlich hergestellten Substanzen oder devitalem Material natürlicher Herkunft und dienen dem Ersatz fehlender Körperteile (z.B. Zahnimplantat) oder als Trägermaterial für Substanzen (z.B. Carrier in Studien). Bei den Materialien natürlicher Herkunft werden durch Lyophilisation, Autoklavierung und Hitzebehandlung antigenetisch wirksame Zellen und immunogene Eiweißbestandteile inaktiviert/zerstört.

Unterscheiden lassen sich die Implantatmaterialien in organische und anorganische Materialien. Zu den organischen Substanzen zählen Materialien wie Kollagen, Polylaktide (PLA) oder Polyethylenglykol (PEG). Anorganische Materialien sind bspw. die Trikalziumphosphate, Kalziumkarbonate oder Titan.

Eine weitere Unterscheidung ist möglich in resorbierbare (Kollagen, Polymere) und nicht resorbierbare Materialien (Titan).

Synthetisch hergestellte Implantatmaterialien (z.B. Polymere) sind zwar fast unbegrenzt verfügbar, haben hinsichtlich ihrer Einheilung und Einbindung ist das Gewebe jedoch nicht ganz so gute Eigenschaften wie natürliche Gewebe (Foitzik und Merten 1999, Kübler 1997, Ratner et al. 2004, Schwenzer und Ehrenfeld 2002).

\subsection{Trägermaterialien}

Implantatmaterialien können mit bestimmten Substanzen, z.B. Wachstumsfaktoren beschichtet werden, um eine schnellere Knochenregeneration herbeizuführen. Sie dienen dann als Trägermaterial. Der Einsatz eines Trägermaterials (Carriers) verbessert die Reproduzierbarkeit von Ergebnissen in Versuchen mit Knochenwachstumsfaktoren und scheint die Knocheninduktion zu steigern (Sakou 1998). 
Trägermaterialien haben den Zweck, bestimmte Substanzen, in diesem Fall Wachstumsfaktoren, an einem bestimmten Ort konzentriert einbringen und dort eine gewisse Zeit halten zu können. Die Trägermaterialien sollen dabei eine reversible Bindung und konstante Freisetzung von Wachstumsfaktoren gewährleisten. Sie sollten gewebeverträglich sein und keine Fremdkörperreaktionen hervorrufen (Bostrom et al. 1998, Boyan et al. 1999, Friedländer et al. 2001, Gao et al. 1993, Kawamura und Urist 1988, Hollinger et al. 1998, Itoh et al. 1998, Kirker-Head 1995, Kuboki et al. 1998, Ruppert et al. 1996, Schwartz et al. 1998, Winn et al. 1998, Winn et al. 1999).

Die osteokonduktiven Eigenschaften sind erwünscht, jedoch sollte das Trägermaterial resorbierbar sein - im Idealfall stimmt die Resorptionsrate des Carriers mit der des Knochenaufbaus überein (Winn et al. 1998).

Langsam resorbierbare Materialien (z.B. Hydroxylapatit) verzögern zwar den Remodeling-Prozess, gewährleisten jedoch über einen längeren Zeitraum Stabilität und können so bei mechanisch beanspruchten Defekten ihren Einsatz finden (Johnson und Urist 2000, Kusumoto et al. 1997).

Eine gute Verfügbarkeit und leichte Handhabe sind ebenfalls Eigenschaften, die ein Carrier erfüllen sollte (Li und Wozney 2001). Charakteristika wie die Ladung, die Oberflächenbeschaffenheit des Materials oder dessen Porengröße nehmen weiteren Einfluss auf die Angionese und das Einwachsen neuen Knochens (Kuboki et al. 1995, Kuboki et al. 1998, Lane et al. 1999, Murata et al. 1998, Ripamonti und Reddi 1992, Sasano et al. 1993, Tsuruga et al. 1997, Uludag et al. 2000). 


\subsection{Trägerbeladung und Freisetzungskinetik}

Die Beladung der Trägermaterialien kann auf verschiedene Arten erfolgen.

Die einfachste Art ist hierbei ein Tränken des Carriers in einer Lösung mit der gewünschten Konzentration des Wachstumsfaktors.

Es hat sich jedoch gezeigt, dass es bei diesem Verfahren zu einer sehr raschen Freisetzung des Wachstumsfaktors innerhalb der ersten 24-48 Stunden kommt und nicht die gewünschte langanhaltende, kontinuierliche Freisetzung erzielt werden kann (Uludag et al. 2000). Um eine länger anhaltende Freisetzung zu erreichen, müssten weit höhere Dosen des Wachstumsfaktors eingesetzt werden. Ziel der Forschung ist es jedoch möglichst geringe knocheninduzierende Konzentrationen an Wachstumsfaktoren einzusetzen, die über längere Zeit nach und nach freigesetzt werden und so die physiologischen Verhältnisse der Knochenheilung am ehesten imitieren.

Es wurde daher versucht Beladungsmethoden zu entwickeln, die eine langsame kontinuierliche Freisetzung der Wachstumsfaktoren erlauben. So wurden beispielweise organische Zusätze verwendet, um die Wachstumsfaktoren länger an die Träger zu binden (Cleland et al. 2001, Hu et al. 2001, King und Patrick 2000). 1996 verwendeten Tschakaloff et al. als erste die Methode der Begasung von Polylaktiden. Hierbei wurden die Polylaktidträger unter hohem $\mathrm{CO}_{2}$-Druck begast, so dass sie sich verflüssigten und die Wachstumsfaktoren einschlossen. Diese Methode wurde im Verlauf der Jahre auch von anderen Autoren als erfolgreiches Modell beschrieben, Wachstumsfaktoren in Polymere einzubringen, um ein kontinuierliches Freisetzungssystem zu erhalten (Harris et al. 1998, Hile et al. 2000, Howdle et al. 2001, Mooney et al. 1996).

Schliephake et al. veröffentlichten 2007 eine In-vitro-Studie, bei der Polylaktidträger durch $\mathrm{CO}_{2}$-Begasung den Wachstumsfaktor rh-BMP-2 einschlossen. Sie beobachteten die Freisetzung des Wachstumsfaktors über eine Zeitspanne von 27 Tagen. 
Dabei zeigte sich eine anfänglich rasche Freisetzung innerhalb der ersten 9 Tage, die überging in eine langsamere kontinuierliche Freisetzung zum Ende der Beobachtungsperiode.

Ein Modell, um die osteoinduktive Potenz solcher Systeme zu testen, ist der critical size defect. Unter einem critical size defect versteht man einen Knochendefekt definierter Größe, bei dem es zu keiner spontanen knöchernen Regeneration mehr kommt. Die Größe ist dabei sowohl von der Spezies als auch von der Lokalisation des Defekts abhängig (Aaboe et al. 1994, Bosch et al. 1998, Hollinger und Kleinschmidt 1992). Kommt es nach Zusatz von Wachstumsfaktoren zur knöchernen Durchbauung eines critical size defects, so erhält man in ihr ein Maß für die osteoinduktive Eigenschaft der getesteten Substanz.

\subsection{Wachstumsfaktoren}

Im menschlichen Körper gibt es eine Reihe von Wachstumsfaktoren, die die Entwicklung, Differenzierungs -und Reparaturvorgänge steuern. Im Folgenden soll nur ein kurzer Überblick über einige wichtige Wachstumsfaktoren erfolgen.

PDGF (Platelet Derived Growth Factor) spielt eine wichtige Rolle bei der embryonalen Entwicklung verschiedener Gewebe und Organe. Bei der Frakturheilung wird PDGF von Thrombozyten des Frakturhämatoms freigesetzt und stimuliert dort mesenchymale Zellen und Fibroblasten (Abendroth 1992, Mohan und Baylink 1991). 
$\underline{\text { FGF (Fibroblast Growth Factor) }}$ übt einen mitogenen Effekt auf Mesenchymzellen, Fibroblasten, Chondroblasten und Osteoklasten aus und hat zudem eine angiogene Wirkung. Daher spielt dieser Faktor z.B. in der frühen Knochenheilung eine Rolle (Barnes et al. 1999, Bostrom et al. 1999, Mohan und Baylink 1991, Nakajima et al. 1998, Wang JS und Aspenberg 1996).

\section{$\underline{\text { IGF (Insulin Like Growth Factor) }}$}

Bei diesem Faktor unterscheidet man zwischen IGF I und IGF II, wobei IGF I eine höhere Wirkung zugesprochen wird. Während IGF II die embryonale Skelettentwicklung stimuliert, spielt IGF I im späteren Leben bei Synthese und Reparaturvorgängen von Knorpel-, Knochen-, Sehnen- und Muskelgeweben eine Rolle (Hock et al. 1988, Prisell et al. 1993, Rinderknecht und Humbel 1978, Trippel et al. 1996).

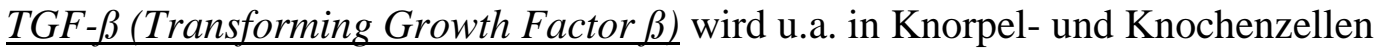
gebildet und anschließend in der Knochenmatrix oder in Thrombozyten gespeichert. Bei einer Fraktur kommt es zur Freisetzung des Faktors und zur Stimulierung von Mesenchymzellen und Chondrozyten (Barnes et al. 1999, Bolander 1992, Bostrom und Asnis 1998, Centrella et al. 1991, Centrella et al. 1994, Einhorn 1998, Joyce et al. 1990b, Robey et al. 1987, Rosier et al. 1998, Sandberg et al. 1988, Trippel et al. 1996, van den Eijnden-van Raaij et al. 1988).

BMP (Bone Morphogenetic Protein) spielt ebenfalls eine große Rolle im Rahmen der embryonalen Entwicklung und bei der Knochenheilung. Es stimuliert die Differenzierung von Mesenchymzellen zu Chondroblasten und Osteoblasten und ist der einzige Wachstumsfaktor, der allein in der Lage ist neues Knochenwachstum zu induzieren (Hogan 1996a, Hogan 1996b, Kübler 1997, Paralkar et al. 2002, Reddi 2000a, Urist 1965). 
Da BMP-2 auch Gegenstand dieser Arbeit ist, wird im nächsten Abschnitt noch genauer auf die BMPs und ihre Wirkungsweise eingegangen.

\subsubsection{BMP-Historie}

1965 und 1979 führte Urist in tierexperimentellen Untersuchungen eine intramuskuläre Implantation mit demineralisiertem Knochen (DBM demineralized bone matrix) durch (Urist 1965, Urist et al. 1979).

Sie beobachteten dabei eine De-novo-Knochenbildung im heterotopen Gewebe und stellten die These auf, dass sich in der Matrix Proteine mit osteoinduktiven Eigenschaften befinden müssten, die Urist als Bone Morphogenetic Proteins (BMPs) bezeichnete (Kübler 1997, Paralkar et al. 2002, Urist 1965, Urist et al. 1967). Seither wurden diese Proteine vielfältig erforscht und bis heute konnten über 40 verschiedene BMPs isoliert, charakterisiert und zum Teil rekombinant hergestellt werden (Ducy und Karsenty 2000).

Obwohl BMPs vielfache Aufgaben - gerade in der embryonalen Entwicklung haben, nehmen die meisten von ihnen Einfluss auf die Knorpel- und Knochenbildung, indem sie die Proliferation und Differenzierung pluripotenter Mesenchymzellen zu Chondro- und Osteoblasten induzieren (Barnes et al. 1999, Bostrom und Asnis 1998, Cunningham et al. 1992, Hogan 1996a, Hogan 1996b, Korchynsky und ten Dijke 2002, Lind et al. 1996, Martinovic et al. 2002, Reddi 1994). Es handelt sich bei BMPs um dimere Moleküle (zwei über Disulfidbrücken verbundene Polypeptidketten), die in Osteoprogenitorzellen und Osteoblasten gebildet und in der extrazellulären Matrix des Knochengewebes gespeichert werden (Barnes et al. 1999, Nickel et al. 2002, Reddi 1998, Reddi 2001, Wozney und Rosen 1998). BMPs zeigen eine hohe evolutionäre Konstanz, d.h. es finden sich auch zwischen verschiedenen Spezies weitestgehend identische Aminosäuresequenzen (Ozkaynak et al. 1991, Paralkar et al. 2002, Sampath und Reddi 1983, Urist et al. 1979, Wozney et al. 1988). 
Eine Übersicht einiger der bisher entdeckten BMPs gibt die folgende Tabelle 1.

\begin{tabular}{|l|l|l|}
\hline Name & Alternative Bezeichnung & Potentielle Funktion \\
\hline BMP-2 & BMP-2A & $\begin{array}{l}\text { Knochen- und } \\
\text { Knorpelmorphogenese }\end{array}$ \\
\hline BMP-3 & Osteogenin & Knochenbildung \\
\hline BMP-3B & GDF-10 & Knochenbildung \\
\hline BMP-4 & BMP-2B & $\begin{array}{l}\text { Knochen- und } \\
\text { Knorpelmorphogenese }\end{array}$ \\
\hline BMP-5 & - & Knochenmorphogenese \\
\hline BMP-6 & Vgr-1 & Knorpelhypertrophie \\
\hline BMP-7 & OP-1 & Knochendifferenzierung \\
\hline BMP-8 & OP-2 & Knochenbildung \\
\hline BMP-12 & GDF-7, & $\begin{array}{l}\text { Bänder- und } \\
\text { Sehnenentwicklung }\end{array}$ \\
\hline BMP-13 & GDF-6, & $\begin{array}{l}\text { Knorpelentwicklung und } \\
\text {-hypertrophie }\end{array}$ \\
\hline BMP-14 & $\begin{array}{l}\text { GDF-5, CDMP-1, } \\
\text { CDMP-2 }\end{array}$ & $\begin{array}{l}\text { Mesenchymverdichtung } \\
\text { und Chondrogenese }\end{array}$ \\
\hline
\end{tabular}

Tab. 1: Übersicht über BMPs (Ramoshebi et al. 2002, Rueger DC 2002)

BMP: Bone Morphogenetic Protein

OP: Osteogenic Protein

Vgr: Vegetal (Protein) Related

CDMP: Cartilage Derived Morphogenetic Protein 


\subsubsection{BMP-Rezeptoren und Signalübertragung}

Bone Morphogenetic Proteins binden an transmembranöse Rezeptoren mit einer Serin/Threonin-Kinase-Aktivität (Aoki et al. 2001, Korchynsky und ten Dijke 2002, Nickel et al. 2002, Reddi 2001, Rueger DC 2002, Yamashita et al. 1996).

Dabei kann man zwischen einem Typ-I- und einem Typ-II-Rezeptor unterscheiden, wobei BMPs für ersteren eine höhere Affinität zeigen (Heldin et al. 1997, Massagué 1998).

Um eine Aktivierungskaskade auszulösen, ist allerdings ein heteromerer Komplex aus Typ-I- und Typ-II-Rezeptor notwendig (Koenig et al. 1994, Korchynsky und ten Dijke 2002, Liu et al. 1995, Massagué 1998, Nohno et al. 1995, Piek et al. 1999, Rosenzweig et al. 1995, ten Dijke et al. 1994, Yamashita et al. 1995).

So wird nach der Bindung von BMP an den Typ-I-Rezeptor der Typ-II-Rezeptor miteinbezogen, wodurch es zur Phosphorylierung von intrazellulären Proteinen sogenannten Smads - kommt (Cárcamo et al. 1994, Korchynsky und ten Dijke 2002, Massagué 1998, Piek et al. 1999, Reddi 2001).

Der Begriff „Smad“ setzt sich zusammen aus Sma (small body size) und Mad (mother against decapentaplegic), zwei Genen, die in unterschiedlichen Spezies entdeckt wurden und für die anschließend eine gemeinsame Nomenklatur gesucht wurde (Heldin et al. 1997, Korchynsky und ten Dijke 2002, Reddi 2001, Savage et al. 1996, Sekelsky et al. 1995).

Es gibt aktive R-Smads, Co-Smads und inhibierende I-Smads (Korchynsky und ten Dijke 2002, Nakao et al. 1997, Reddi 2001, Rueger DC 2002).

Nachdem der Rezeptorkomplex aktiviert wurde, kommt es zur Phosphorylierung eines R-Smads, das mit Hilfe eines Co-Smads in den Nukleus eindringt (Correia et al. 2001, Ebisawa et al. 1999, Heldin et al. 1997, Kawabata et al. 1998, Lagna et al. 1996, Massagué 1998, Nishimura et al. 1998, Rueger DC 2002, Shi et al. 1997). 
Vermittelt durch weitere DNA-bindende Proteine koppelt dieser Komplex an das spezifische Zielgen und löst dessen Transkription aus (Massagué und Wotton 2000, Paralkar et al. 2002, ten Dijke et al. 2000).

Inhibierende I-Smads unterbinden eine solche Transkription indem sie kompetitiv zu den R-Smads an die Bindungsstelle der Rezeptorkomplexe binden und so eine Aktivierung der R-Smads verhindern und die Aktivierungskaskade unterbrechen (Hayashi et al.1997, Imamura et al. 1997, Nakao et al. 1997).

\subsection{3 rh-BMP-2}

BMP ist in geringen Mengen in der Knochenmatrix gespeichert (Baylink et al. 1993, Joyce et al. 1990a). Um genügend Material für wissenschaftliche Untersuchungen $\mathrm{zu}$ gewinnen, kann zum Einen auf aus Rinderknochen gewonnenes bovines BMP zurückgegriffen werden (Katoh et al. 1993, Lindholm et al. 1988). Mittlerweile gibt es jedoch auch Möglichkeiten rekombinantes BMP gentechnisch herzustellen.

Diese BMPs erhalten dann das Präfix ,rh“ und werden beispielsweise in bakteriellen Expressionssystemen wie E.coli gewonnen.

\subsection{Zielsetzung}

Bei der Behandlung von komplizierten Frakturen und großen Defekten eröffnet die Möglichkeit der rekombinanten Herstellung von osteoinduktiven Substanzen wie rh-BMP-2 der heutigen Knochenchirurgie neue Möglichkeiten und Therapiekonzepte (Ducy und Karsenty 2000). 
Untersucht wurden Wachstumsfaktoren in der Vergangenheit in einer Vielzahl von Studien, insbesondere TGF-B, IGF I, BMP-2, BMP-4 und BMP-7 (Arosarena und Collins 2005b, Aspenberg et al. 1996, Beck et al. 1993, Boyne et al. 2006, Busch et al. 1996, Hock et al. 1988, Hyun et al. 2005, Pang et al. 2004, Roldan et al. 2004, Schliephake 2002, Thaller et al. 1993).

Für die Stimulation von Knochen zeigte sich dabei besonders BMP-2 als potenter osteoinduktiver Faktor (Boyne 1996, Chu et al. 2007, Marukawa et al. 2001, Nagao et al. 2002, Valentin-Opran et al. 2002, Zegzula et al. 1997).

Eine Reihe von Materialien wie Hydroxylapatit, Kalziumphosphate, Titanmeshs, Kollagen und Polymere wurde hinsichtlich ihrer Eignung als Carrier zum Einbringen der Substanzen untersucht. Osteoinduktive Fähigkeiten haben Wachstumsfaktoren wie BMPs (Bone Morphogenetic Proteins) dabei sowohl mit organischen als auch mit anorganischen Carriern bewiesen (Bouxsein et al. 2001, Gao et al. 1993, Kawamura und Urist 1988, Lee et al. 1999, Winn et al. 1999). Einige Trägermaterialien erwiesen sich als $\mathrm{zu}$ weich, um einen mechanisch stabilisierenden Effekt auf die Fraktur bzw. den Defekt ausüben zu können oder es kam lediglich zu einem schnellen Freisetzen des Wachstumsfaktors aus dem Trägermaterial und nicht zu der gewünschten langanhaltenden, kontinuierlichen Abgabe (Kim et al. 2005, Kanematsu et al. 2004, Oliveira et al. 2006, Seeherman et al. 2006, Uludag et al. 2000, Vehof et al. 2001).

Speziell begaste Polylaktidimplantate haben sich in einer In-vitro-Vorstudie als geeignetes System erwiesen, um rh-BMP-2 einzuschließen und anschließend kontrolliert und langanhaltend freizusetzen (Schliephake et al. 2007).

Ziel dieser Arbeit war es, zu überprüfen, ob die kontrollierte langsame Freisetzung von rh-BMP-2 aus solchen vorgeformten Polylaktidimplantaten zu einer Knocheninduktion und Defektüberbrückung bei Defekten kritische Größe in vivo führt. Zudem sollte untersucht werden, ob sich Unterschiede zu den Kollagenträgern dieser Studie verzeichnen lassen, die lediglich mit gleichen Konzentrationen des Wachstumsfaktors getränkt wurden. 


\section{MATERIAL UND METHODEN}

\section{1 rh-BMP-2}

In dieser Studie wurde rekombinantes rh-BMP-2 verwendet, da BMP-2 zu einer in Vorstudien erwiesenen zuverlässigen De-novo-Knochensynthese führt (Kübler 1999, Wang EA et al. 1990).

Der Wachstumsfaktor rh-BMP-2 stammte vom Helmholtzinstitut (ehemals GBF -

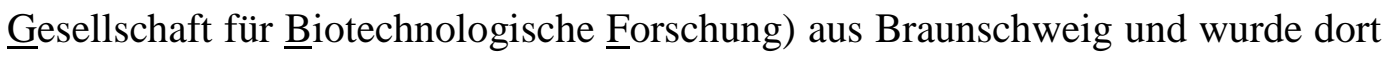
rekombinant in E.coli hergestellt (Schliephake et al. 2007).

Geliefert wurde das rh-BMP-2 als Pulver in lyophilisierter Form.

Um die Menge an rh-BMP-2 quantifizieren zu können, wurde ein spezieller von Dr. Mark Hennies entwickelter ELISA verwendet, der in der Lage ist im bakteriellen E.coli System hergestelltes bac-rh-BMP-2 zu bestimmen.

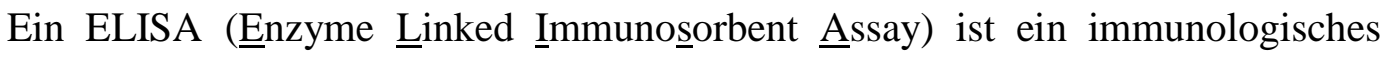
Nachweisverfahren, das durch Antikörper-Antigen-Koppelung mittels angehefteter Enzyme und daraus resultierenden Farbumschlags bestimmte Proteine, Hormone und auch Wachstumsfaktoren erkennen und quantitativ darstellen kann. Bei dem hier verwendeten ELISA handelte es sich um einen kompetitiven Test mit 2. Antikörper und Biotin-Streptavidinsystem.

Die Enzymreaktion der Proben wurde in einer Mikrotiterplatte im Photometer Genion Plus der Firma Tecan, Crailsheim gemessen und der rh-BMP-2-Gehalt so quantifiziert. 


\subsection{Polylaktidträger}

Ein Trägermaterial, das in dieser Studie verwendet wurde, waren Polylaktidimplantate. Dieses Material (Poly-D,L-Milchsäure =PDLLA) ist ein synthetisch hergestelltes resorbierbares Polymer.

Bei Milchsäure handelt es sich um ein natürliches Molekül, welches vom Körper abgebaut wird (Kulkarni et al. 1966, Laurencin und Lane 1994).

Polylaktide eignen sich auf Grund ihrer Stabilität und Formgebung gut für mechanisch belastete Defekte (Winn et al. 1998, Hile et al. 2000).

Die Polylaktidgranula zur Herstellung der Implantate stammte vom Unternehmen Boehringer, Ingelheim. (Resomer 208, logarithmische Viskositätszahl 1,8 dl/g)

\subsection{Kollagenträger}

Als weiteres Trägermaterial wurde Kollagen untersucht. Das hier verwendete Produkt war Kollagen Resorb, ein lyophilisiertes Kollagen-Vlies der Firma Resorba CliniCare $\AA$, Nürnberg. Gewonnen wird dieses Material aus Kollagenfibrillen equinen Ursprungs (Pferdesehnen).

Kollagen ist ein rasch resorbierbares Material, welches sich durch seine gute Formbarkeit und Handhabe auszeichnet (Horisaka et al. 1994).

Weitere Vorteile dieses Materials sind neben seiner Biokompatibilität und der pHStabilität, die angiokonduktive Wirkung und die Funktion als Knochenleitstruktur (Osteokonduktivität) (Riedel und Valentin-Opran 1999).

Jedoch ist Kollagen auf Grund seiner weichen Beschaffenheit nicht in der Lage stabilisierend auf Defekte zu wirken. 


\subsection{Versuchstiere}

\subsubsection{Tierart}

Für die Versuche wurden 45 männliche Wistar-Kyoto-Ratten mit einem Alter von 6 Monaten und einem Durchschnittsgewicht von 426g Gramm untersucht. Die Tiere stammten von der Firma Harlan Winkelman GmbH aus Borchen und aus hauseigener Züchtung.

Ratten zeigen gegenüber Menschen eine schnellere Frakturheilung, die zu einem Zeitraffereffekt führt und bei der Übertragung der Ergebnisse auf Menschen berücksichtigt werden muss. Das Verhältnis Ratte : Mensch beträgt dabei 5:1 (Coulson 1983, Sato und Urist 1985).

\subsubsection{Haltung und Fütterung}

Die Tiere wurden bei Raumtemperatur $21+-2^{\circ} \mathrm{C}$ in Vierergruppen in Makrolonkäfigen Typ 4 mit einer Grundfläche von $1820 \mathrm{~cm}^{2}$ gehalten. Die Luftfeuchtigkeit lag bei $45+-10 \%$ und die Tiere hatten einen 12 Stunden Tagund-Nacht-Rhythmus. Als Einstreu dienten handelsübliche Holzspäne. Gefüttert wurde ad libitum mit dem Standard Nagerfutter der Firma Ssniff. Die Wasserversorgung der Tiere erfolgte ebenfalls ad libitum mit normalem Leitungswasser. 


\subsection{Herstellung der Implantate}

Um die Polylaktidgranula mit dem Wachstumsfaktor zu versehen, wurde das gelieferte rh-BMP-2 als wässrige Lösung unter die DL-Polylaktidgranula gemischt, lyophilisiert und bei $-80^{\circ} \mathrm{C}$ gelagert. Dabei wurden zwei Konzentrationen gebildet : $1600 \mu \mathrm{g}$ rh-BMP-2/ g Polymer und $800 \mu \mathrm{g}$ rh-BMP-2/ g Polymer. Von den so beschichteten Granula wurden jeweils 0,06 $\mathrm{g}$ in vorgefertigte Mulden einer PTFE (Poly-Tetra-Fluor-Ethylen) - Platte gegeben und bei Zimmertemperatur 2 Stunden einer $\mathrm{CO}_{2^{-}}$Hochdruckbegasung bei 100 bar ausgesetzt, bei der die Träger sich verflüssigten und die Wachstumsfaktoren einschlossen (Schliephake et al. 2007).

So entstanden Implantatkörper von $8 \mathrm{~mm}$ Durchmesser und $3 \mathrm{~mm}$ Dicke, die bei der hohen Wachstumsfaktorkonzentration $96 \mu \mathrm{g}$ rh-BMP-2 pro Implantat enthielten und bei der niedrigeren $48 \mu \mathrm{g}$ rh-BMP-2 pro Implantat.

Diese Begasung der Implantate wurde an der Uni Duisburg-Essen, Abteilung Anorganische Chemie unter der Leitung von Prof. Dr. M. Epple durchgeführt.

Bei den Kollagenträgern wurden ebenfalls die beiden Konzentrationen von 96 bzw. $48 \mu \mathrm{g}$ rh-BMP-2 pro Implantat hergestellt. Dazu wurde das Pulver entsprechend mit MES-Puffer (2-(N-Morpholino)ethansulfonsäure) verdünnt, bis die gewünschte Konzentration erreicht war. Anschließend wurden die Kollagenträger bei Zimmertemperatur mit der jeweiligen Lösung beträufelt.

Sowohl bei den Polylaktidträgern als auch bei den Kollagenträgern wurden die beiden gebildeten Konzentrationen in Gruppen von fünf bzw. drei Tieren über verschieden lange Zeiten (6,13 und 26 Wochen) getestet . Trägermaterialien ohne einen BMP-2-Zusatz und reine Leerdefekte dienten als Kontrollen.

Getestet wurden die beiden Trägermaterialien jeweils mit unterschiedlich hohen Konzentrationen über verschieden lange Zeiträume (siehe Tabelle 2). 
Überblick über die Konzentrationen, Zeiten und Implantationsorte :

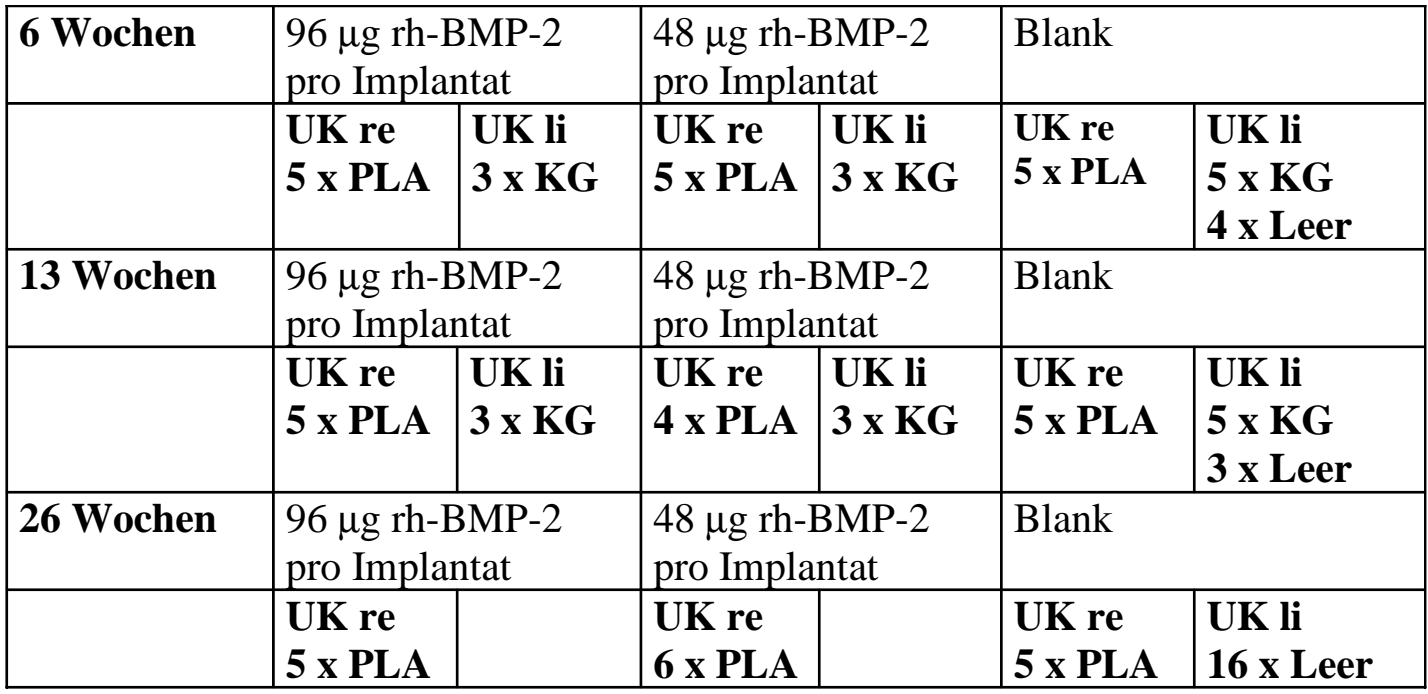

Tab. 2: Konzentrationen, Zeiten und Implantationsorte

$\mathrm{UK}=$ Unterkiefer, $\mathrm{re}=$ rechts, $\mathrm{li}=$ links

PLA $=$ Polylaktidimplantat

$\mathrm{KG}=$ Kollagenimplantat

\section{$2.6 \mathrm{OP}$}

Die Ratten wurden mittels 5 mg/ kg KG Ketamin (100 mg/ml) und 75 mg/ kg KG Xylazin (2\%) narkotisiert. Mit Hilfe eines Rosenbohrers wurde in die Mandibula in Region des Kieferwinkels ein durchgängiger Defekt mit einem Durchmesser von $5 \mathrm{~mm}$ gesetzt. Dieser Defekt ensprach einem critical size defect. In die rechten Unterkiefer wurden die Polylaktidimplantate eingebracht, während die linke Seite die Kollagenträger erhielt. 
Aus den Polylaktidimplantaten wurden dafür zunächst mittels eines Henkellocheisens passende Tabletten von $5 \mathrm{~mm}$ Durchmesser gestanzt und die übrigen Anteile zerkleinert und lateral auf die Implantate aufgelagert.

Die Kollagenträger waren mit $8 \mathrm{~mm}$ etwas größer als der Defekt, ließen sich aber auf Grund ihrer guten Formbarkeit mühelos in die Defekte einbringen, so dass sie sich nach lateral vorwölbten. Tiere, die einen Defekt gesetzt bekamen jedoch keine Implantate erhielten, dienten als Leerkontrollen (siehe Tabelle 2).

Post OP erhielten die Tiere Schmerzmittel (Buprenorphin), um eine mögliche systemische Beeinflussung durch Schmerzreize zu unterbinden.

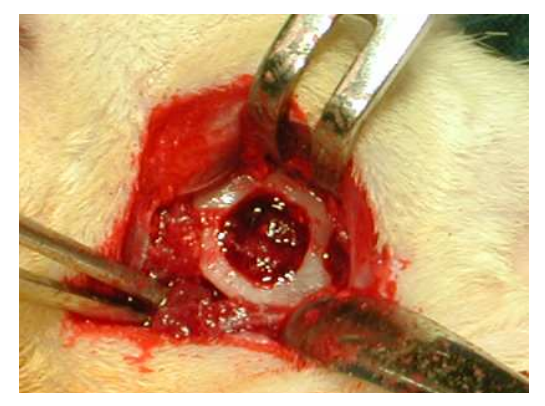

Abb. 1: OP-Bild

Präparierter Defekt

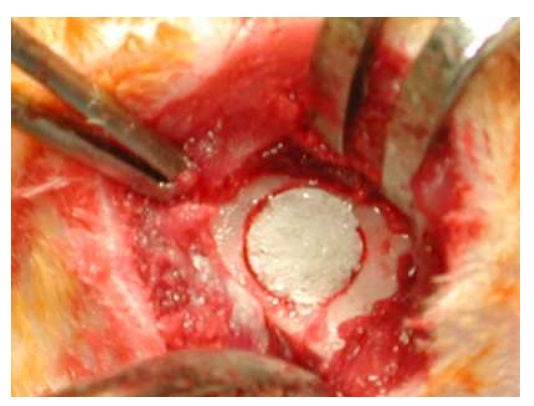

Abb. 2: OP-Bild

Defekt mit inseriertem

Polylaktidimplantat

\subsection{Herstellung der Trenn-Dünnschliff-Präparate}

Nach jeweils 6, 13 und 26 Wochen wurden die Kieferwinkel entnommen und in einer 4\% igen Formalinlösung fixiert. Vor der Einbettung erfolgte eine Entwässerung in aufsteigender Ethanolreihe (jeweils 5 Minuten in $50 \%$ igem, $70 \%$ igem und $2 \times 96 \%$ igem Ethanol) und die Infiltration mit dem Methylmethakrylat Technovit $9100 \AA$, Heraeus Kulzer, Wehrheim. 
Nach einer Aushärtung im Kühlschrank bei $-3^{\circ} \mathrm{C}$ für 48 Stunden wurden die Unterkieferblöcke mit dem Sekundenkleber Loctit 420 (Henkel, Düsseldorf) auf die Objektträger geklebt (Abb.4). Die Blöcke wurden auf ca. $100 \mu \mathrm{m}$ Schichtdicke abgetrennt und anschließend mit Hilfe einer Schleifmaschine (Exakt, Norderstedt) Schliffe in einer Stärke von $50 \mu \mathrm{m}$ zur histologischen Untersuchung hergestellt $($ Abb. $3+5)$.

Für die Polylaktid- und Kollagenträger wurde dabei die gleiche Vorgehensweise angewendet.

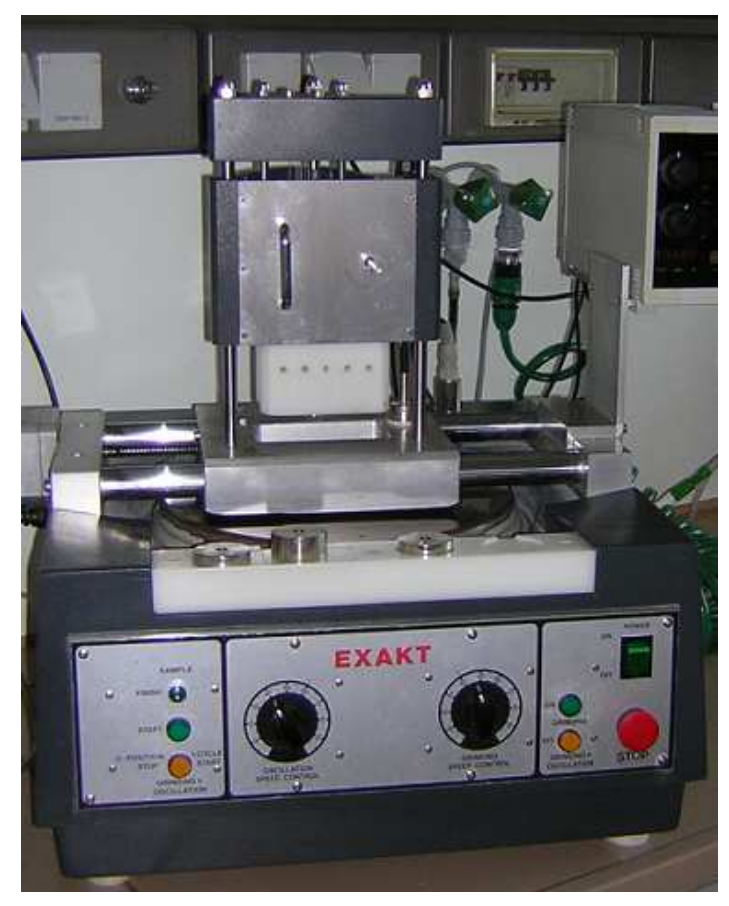

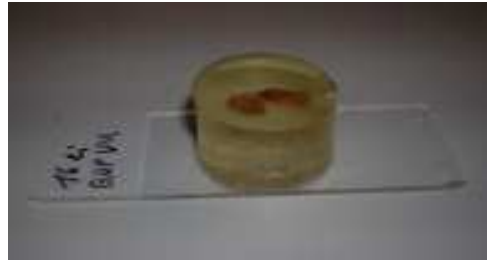

Abb. 4: In Technovit 9100 eingebetteter Unterkiefer

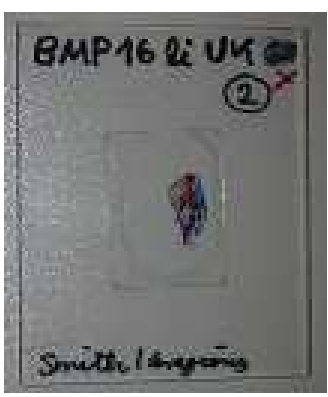

Abb. 5: Fertig geschliffenes und gefärbtes Präparat

Abb. 3: Schleifmaschine der Firma Exakt

Die Schliffe erhielten im Anschluss ihre Färbung nach Smith-Karagianes (Smith und Karagianes 1974). Diese Färbung hat den Vorteil mineralisiertes Gewebe wie Knochen leicht erkenn- und abgrenzbar orange-rot darzustellen und Weichgewebe wie Muskulatur blau. Die Färbung erfolgte mit zwei Farbstoffen, Methylenblau und Alizarin. 
Zunächst wurde das Methylenblau in einem Gefäß mit Magnetrührer auf einer Heizplatte auf $80{ }^{\circ} \mathrm{C}$ erhitzt und die Schliffe für 30 Sekunden eingetaucht.

Anschließend wurde mit Aqua dest. gespült und die Schliffe über Nacht luftgetrocknet. Am nächsten Tag wurde bei Zimmertemperatur 40 Sekunden in Alizarin gefärbt, erneut mit Aqua dest. gespült und über Nacht luftgetrocknet. Nach Eindeckelung der Schliffe am nächsten Tag mit einem Tropfen eines speziellen Klebstoffs für histologische Schliffe (Entellan, Merck, Darmstadt) und erneuter Aushärtung über Nacht waren die Schliffe bereit für die Mikroskopie. Als Schliffebene wurde jeweils ein repräsentativer Schliff durch das Zentrum des Defekts gewählt.

\subsection{Mikroskopie/Untersuchungsmethoden}

Die Auswertung der gefärbten Schliffpräparate erfolgte mit Hilfe eines speziellen computerunterstützten Programms (KS 3003.0 der Firma Zeiss, Jena) an einem Mikroskop.

\subsubsection{Mikroskop}

Mit einem Axiophot Mikroskop der Firma Zeiss, Jena (Abb.6), das über einen Computer an einen Bildschirm Anschluss hatte, wurden die gefärbten Schliffe betrachtet, beurteilt und bei 100 facher Vergrößerung abfotografiert und die Bilder gespeichert.

Da es bei dieser Vergrößerung am Mikroskop nicht möglich war, das gesamte Knochenareal auf einen Bildausschnitt zu bekommen, wurden mehrere Einzelfotografien erstellt und anschließend am Computer wieder zusammengesetzt, so dass ein Übersichtsbild zur Auswertung entstand (Abb.7). 
Durch eine histologische Beurteilung am Mikroskop wurden die neu entstandenen Knochenbezirke festgelegt. Dabei half zum Einen die Betrachtung bei polarisierendem Licht, die die noch lockerere Struktur des neuen Knochens verdeutlichte, zum Anderen auch eine defektbezogene Beurteilung, die bei den Präparaten noch die gesetzten Defekte erkennen ließ.

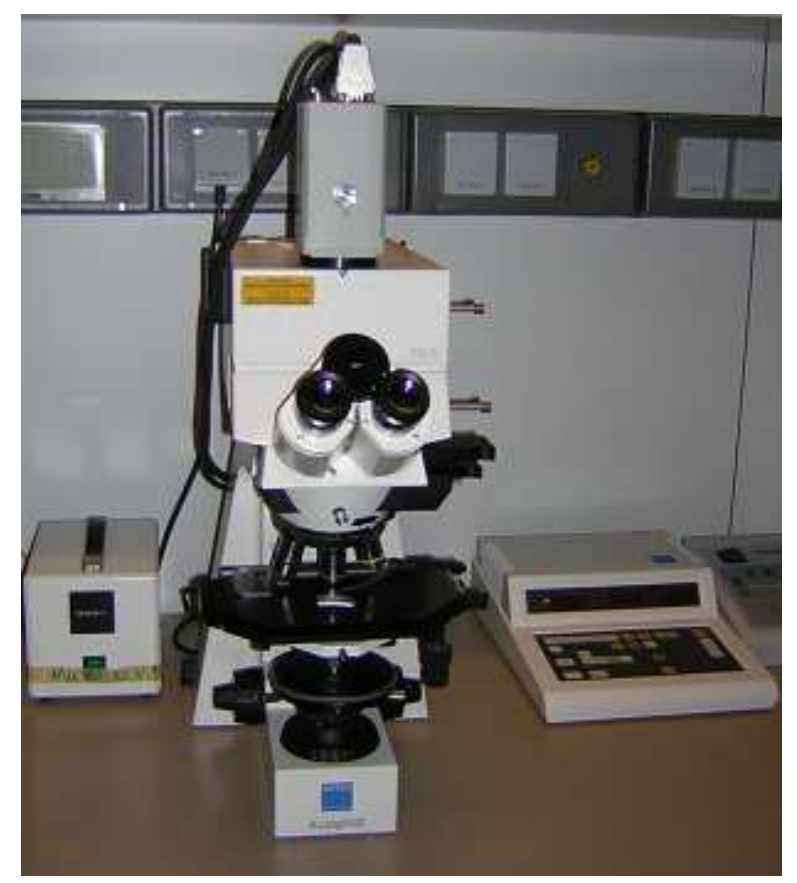

Abb. 6: Mikroskop der Firma Zeiss

\subsubsection{Messprogramm}

Gemessen wurde mit einem speziellen Programm, das markierte Pixel einer Farbe zählen und in Flächen umrechnen kann. 
Da farblich für die automatische Auswertung am Computer kein Unterschied zwischen altem und neuem Knochen auszumachen war und sich so auch andere Bereiche derselben Pixelfarbe des Präparates mitangefärbt und die Messung verfälscht hätten, wurde zunächst manuell die Grenze zwischen altem und neuem Knochen farbig eingezogen (Abb.8) und anschließend die Bereiche des neu entstandenen Knochens mit Hilfe eines Computerprogramms (Microsoft Paint) herausgeschnitten und isoliert gespeichert (Abb.9). In diesen Dateien befand sich nun lediglich der zu vermessende, neu gebildete Knochen. Dieser wurde mit Hilfe des speziellen Programms komplett markiert und vermessen (Abb.10).

Innerhalb der einzelnen Gruppen wurden anschließend die Mittelwerte gebildet.

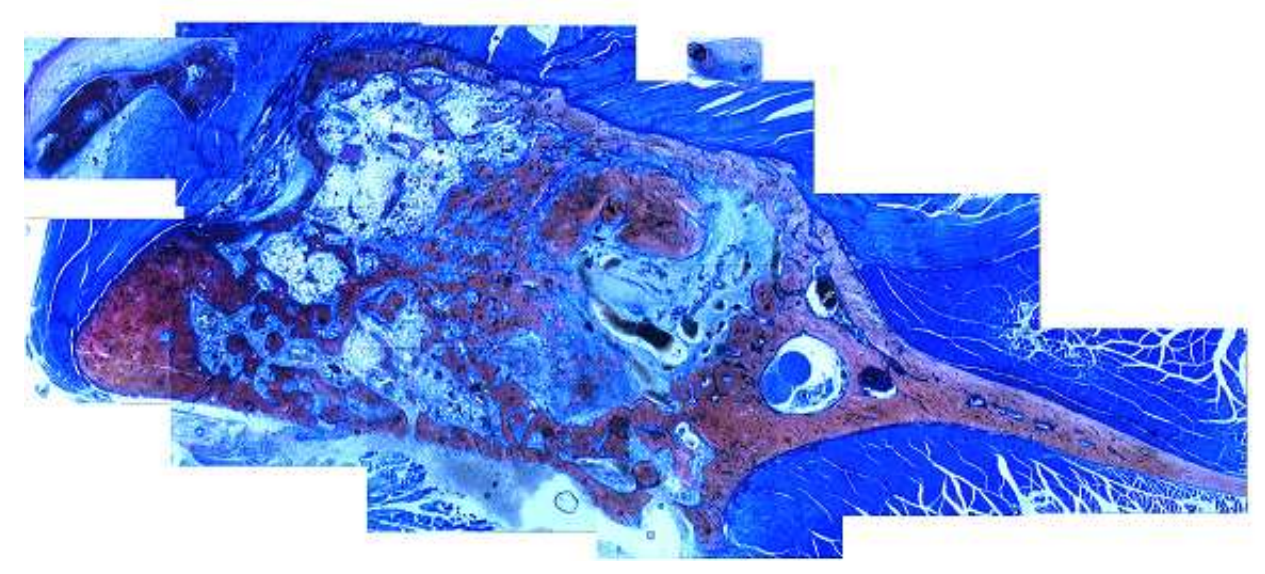

Abb. 7: Zusammengesetztes Ausgangsbild, hier Kollagen, $96 \mu$ g rh-BMP-2 nach 6 Wochen 


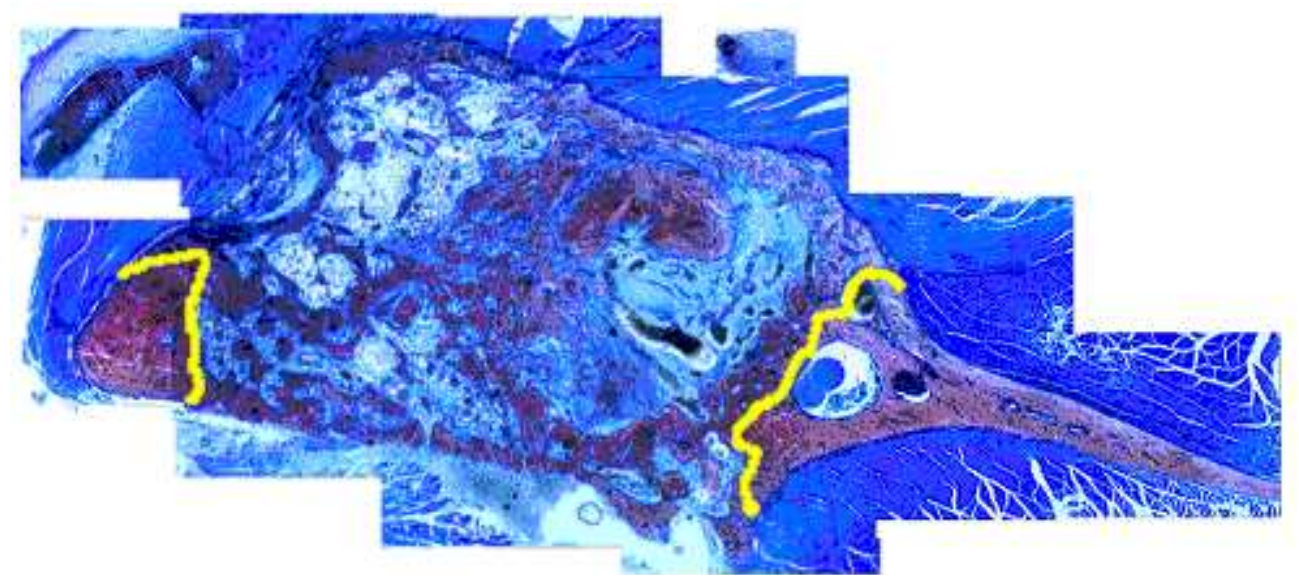

Abb. 8: Gleiches Präparat mit eingezogener Grenze zwischen neuem und altem Knochen

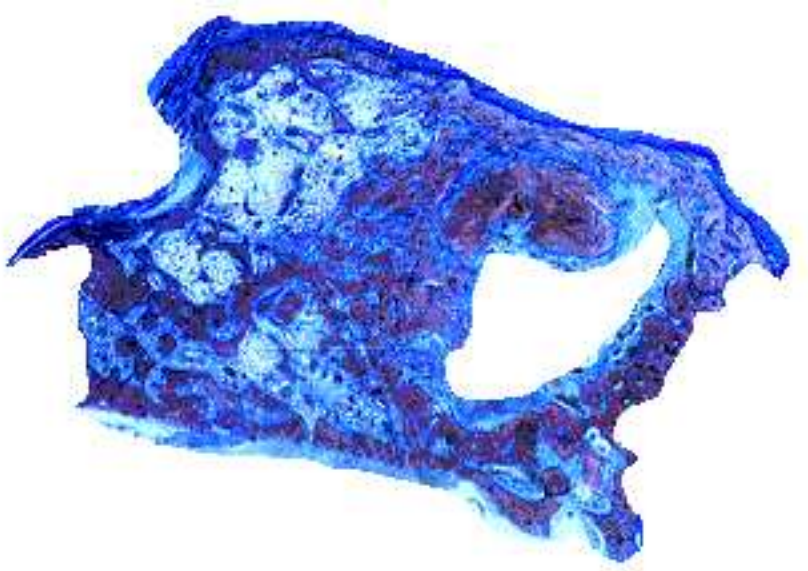

Abb. 9: Zuschnitt, alle die Messung irritierenden Bildausschnitte wurden entfernt

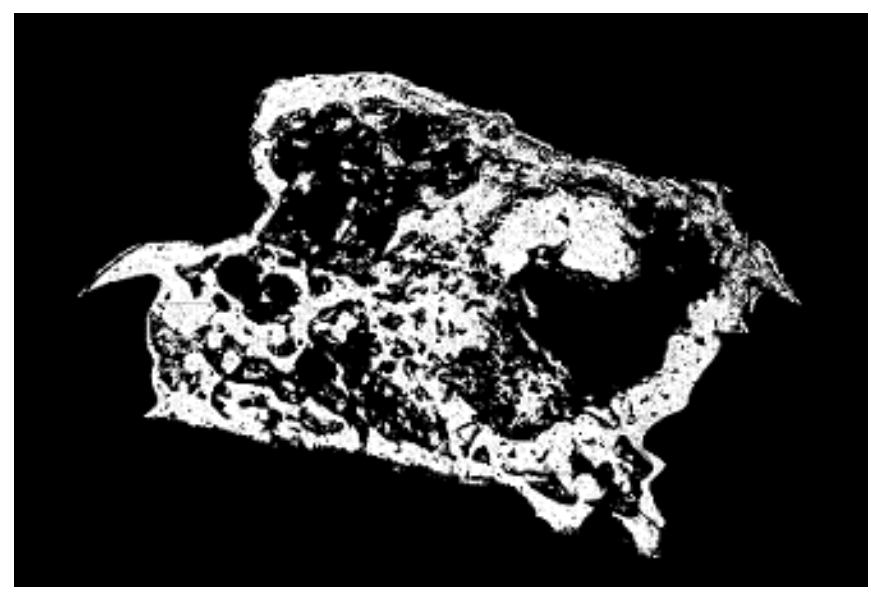

Abb. 10: Messung, neuer Knochen wird weiß dargestellt 


\section{ERGEBNISSE}

\subsection{Polylaktidträger}

\subsection{1 $96 \mu$ rh-BMP-2}

Die $96 \mu \mathrm{g}$ rh-BMP-2-Konzentrationsgruppe der Polylaktidträger zeigte eine deutlich erhöhte Knochenneubildung verglichen mit den Polylaktidträgern ohne rh-BMP-2-Zusatz $(\mathrm{p} \leq 0,001)$ und verglichen mit den reinen DefektKontrollgruppen $(\mathrm{p} \leq 0,001)$. So zeigte sich bei $96 \mu \mathrm{g}$ rh-BMP-2 pro Implantat nach 6 Wochen eine Fläche an neu gebildetem Knochen von 6,69 mm², nach 13 Wochen 5,30 $\mathrm{mm}^{2}$ und nach 26 Wochen $4,36 \mathrm{~mm}^{2}$. Bei den Polylaktidträgern, die keine rh-BMP-2-Beschickung erhalten hatten, betrug die gemessene Fläche nach 6 Wochen $1,11 \mathrm{~mm}^{2}$ und verringerte sich über die Zeit nur gering - 13 Wochen: $0,99 \mathrm{~mm}^{2}, 26$ Wochen: $0,82 \mathrm{~mm}^{2}$ (nicht signifikant $\mathrm{p}>0,05$ ).

Die reinen Leerkontrollen lieferten bei dieser Konzentrationsgruppe nach 6 Wochen Werte von $1,18 \mathrm{~mm}^{2}$, nach 13 Wochen $0,12 \mathrm{~mm}^{2}$ und nach 26 Wochen $0,22 \mathrm{~mm}^{2}$.

\section{Knochenneu- bildung in $\mathbf{m m}^{2}$}

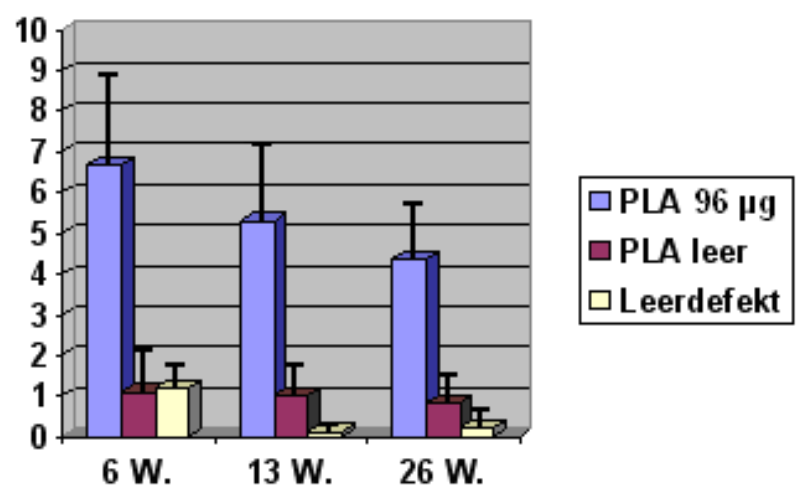

Zeit

Abb. 11: Polylaktidträger der $96 \mu$ g rh-BMP-2-Konzentration im Vergleich zu den leeren Polylaktidträgern und den reinen Leerdefekten 
Innerhalb der $96 \mu \mathrm{g}$ rh-BMP-2-Konzentrationsgruppe nahm die gemessene Fläche an neu gebildetem Knochen über die Zeit kontinuierlich ab. Diese Abnahme war jedoch nicht signifikant $(6 \mathrm{~W}-13 \mathrm{~W}, \mathrm{p}=0,273 ; 13 \mathrm{~W}-26 \mathrm{~W}, \mathrm{p}=0,336)$.

\section{Knochenneu- bildung in $\mathbf{m m}^{2}$}

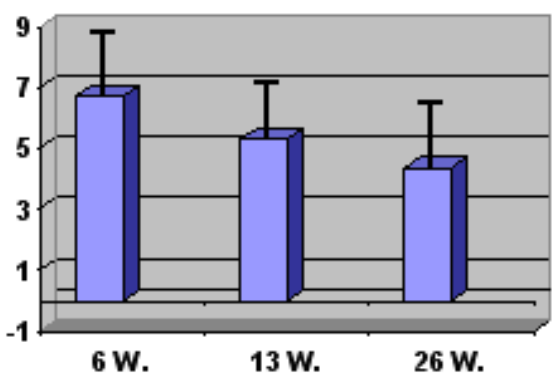

\section{Zeit}

Abb. 12: Polylaktidträger der $96 \mu$ g rh-BMP-2-Konzentration nach 6, 13 und 26 Wochen

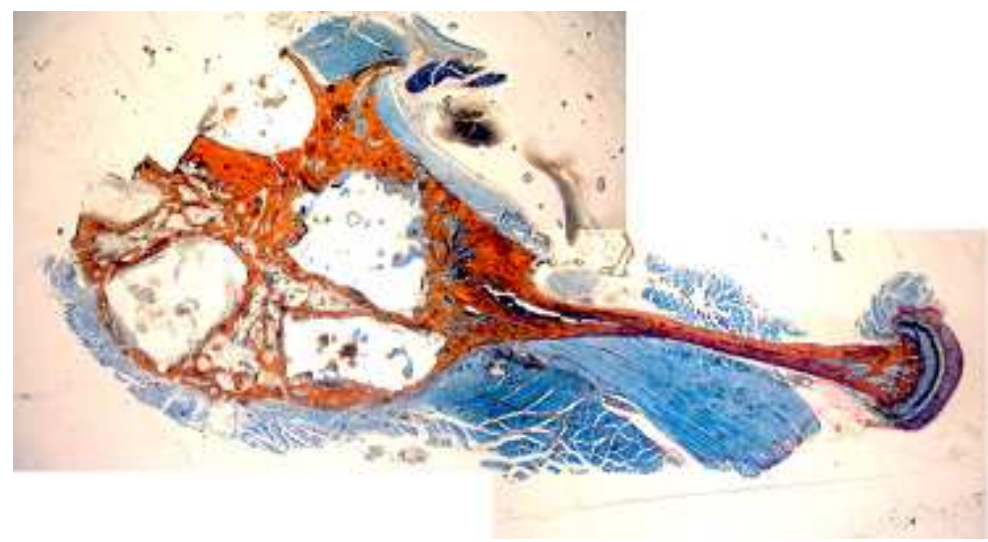

Abb. 13: Polylaktid $96 \mu$ g rh-BMP-2 nach 6 Wochen

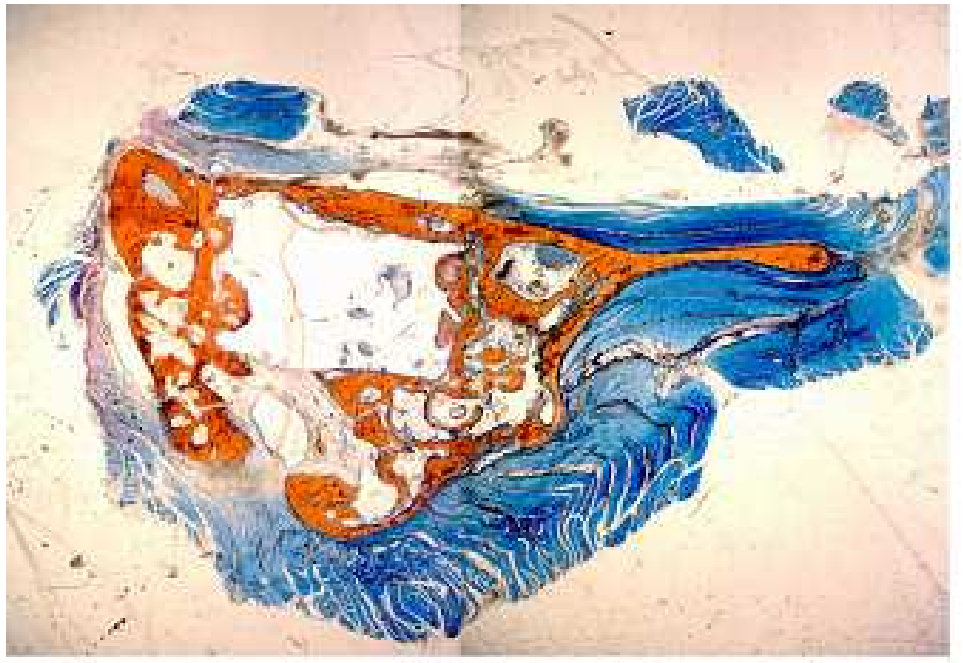

Abb. 14: Polylaktid $96 \mu \mathrm{g}$ rh-BMP-2 nach 13 Wochen 


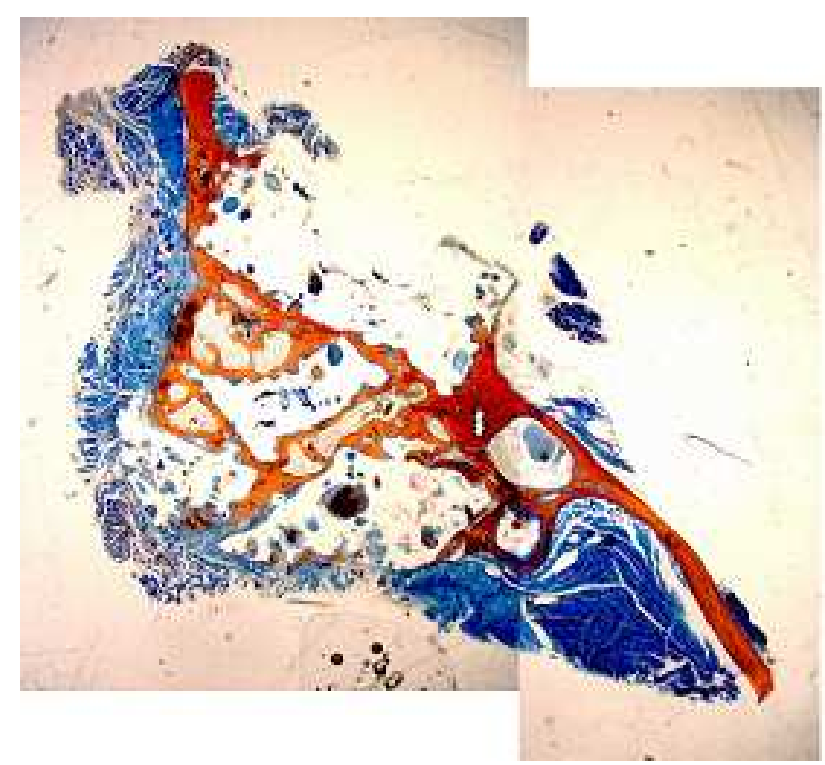

Abb. 15: Polylaktid $96 \mu \mathrm{g}$ rh-BMP-2 nach 26 Wochen

\subsection{2 $48 \mu$ g rh-BMP-2}

Auch die $48 \mu \mathrm{g}$ rh-BMP-2-Konzentrationsgruppe zeigte gegenüber den rh-BMP-2-losen Gruppen ein erhöhtes Maß an Knochenzuwachs. Dieses Ergebnis war für die 6-Wochen-Gruppe signifikant ( $\mathrm{p} \leq 0,001$ ), bei der 13-Wochen-Gruppe nicht ( $\mathrm{p} \geq 0,263$ ) und bei der 26-Wochen-Gruppe nur im Vergleich zu den reinen Leerdefekten $(\mathrm{p} \leq 0,001)$.

\section{Knochenneu- bildung in $\mathbf{m m}^{2}$}

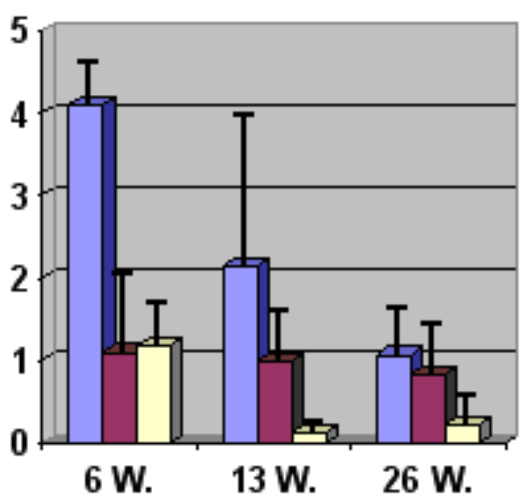

Zeit

Abb. 16: Polylaktidträger der $48 \mu \mathrm{g}$ rh-BMP-2-Konzentration im Vergleich zu den leeren Polylaktidträgern und den reinen Leerdefekten 
Innerhalb der $48 \mu \mathrm{g}$ rh-BMP-2-Konzentrationsgruppe nahm die gemessene Fläche an neu gebildetem Knochen über die Zeit kontinuierlich ab, jedoch nicht sigifikant $(6 \mathrm{~W}-13 \mathrm{~W}, \mathrm{p}=0,155 ; 13 \mathrm{~W}-26 \mathrm{~W}, \mathrm{p}=0,356)$.

Es zeigte sich nach 6 Wochen eine Fläche an neu gebildetem Knochen von 4,11 $\mathrm{mm}^{2}$, nach 13 Wochen $2,15 \mathrm{~mm}^{2}$ und nach 26 Wochen $1,07 \mathrm{~mm}^{2}$.

\section{Knochenneu- bildung in $\mathbf{m m}^{2}$}

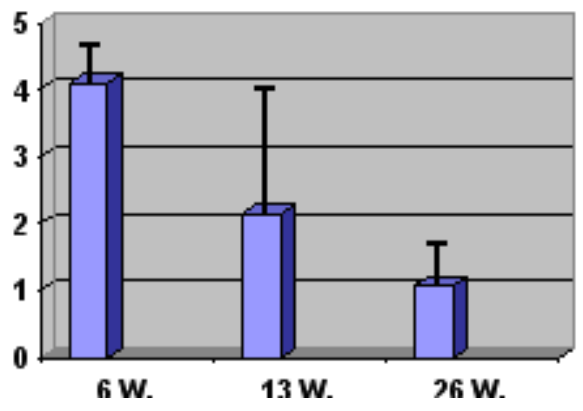

Zeit

Abb. 17: Polylaktidträger der 48 $\mu$ g rh-BMP-2-Konzentration nach 6,13 und 26 Wochen

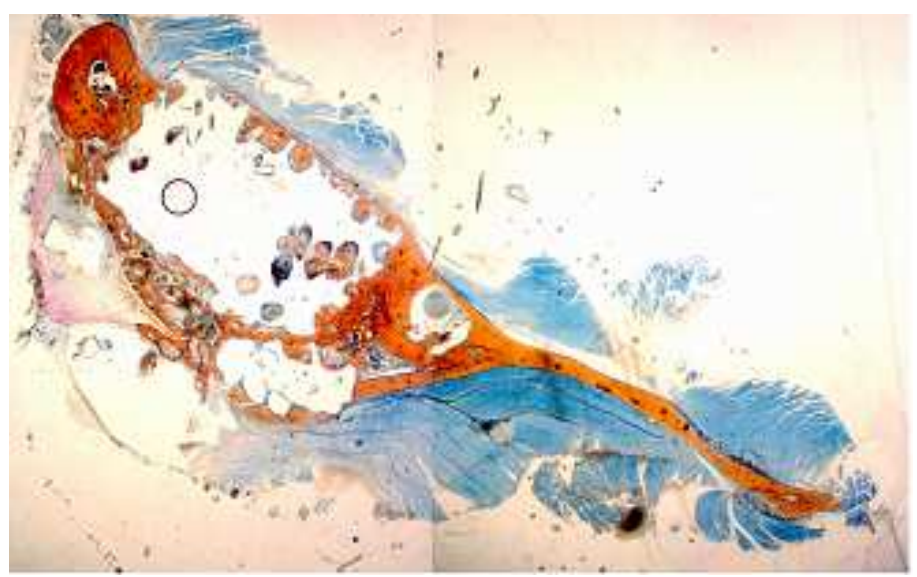

Abb. 18: Polylaktid $48 \mu \mathrm{g}$ rh-BMP-2 nach 6 Wochen

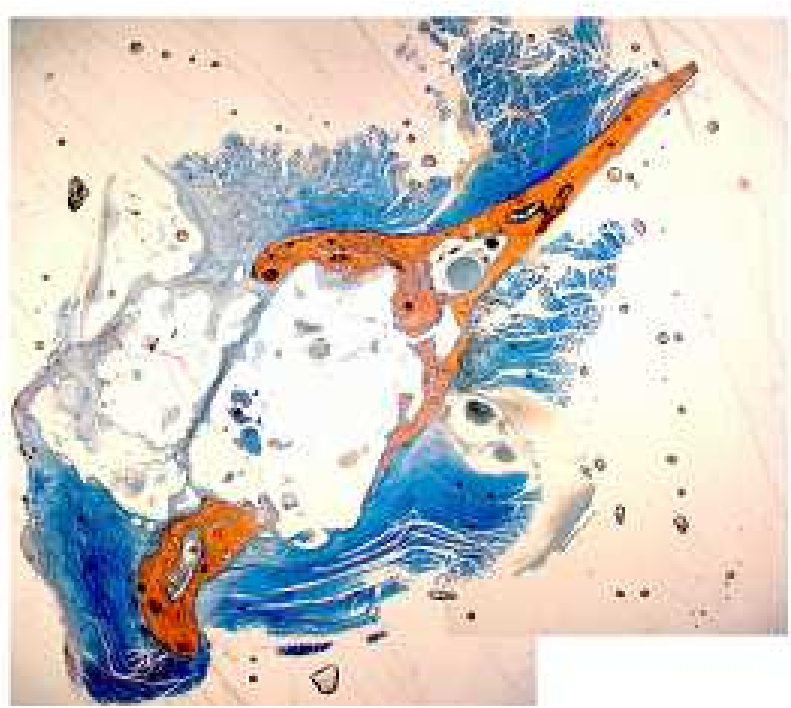

Abb. 19: Polylaktid $48 \mu \mathrm{g}$ rh-BMP-2 nach 13 Wochen 


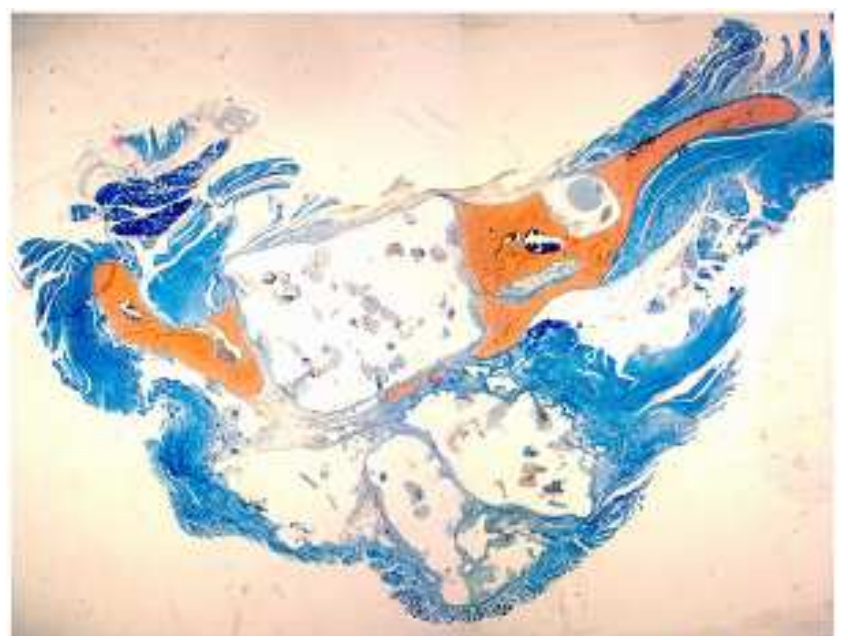

Abb. 20: Polylaktid $48 \mu \mathrm{g}$ rh-BMP-2 nach 26 Wochen

\subsubsection{Vergleich der $96 \mu \mathrm{g}$ - und der $48 \mu \mathrm{g}$-Konzentration}

Beim Vergleich der beiden Konzentrationen untereinander zeigte sich, dass die höhere Konzentrationsgruppe sowohl nach 6, als auch nach 13 und 26 Wochen zu mehr neu gebildetem Knochen führte als die niedrigere rh-BMP-2-Konzentration. Diese Ergebnisse waren für die 6- und 26-Wochen-Gruppe signifikant ( $\mathrm{p} \leq$ 0,027). In der 13-Wochen-Gruppe war die Standardabweichung zu groß um ein signifikantes Ergebnis zu liefern $(p=0,068)$.

\section{Knochenneu- bildung in $\mathbf{m m}^{2}$}
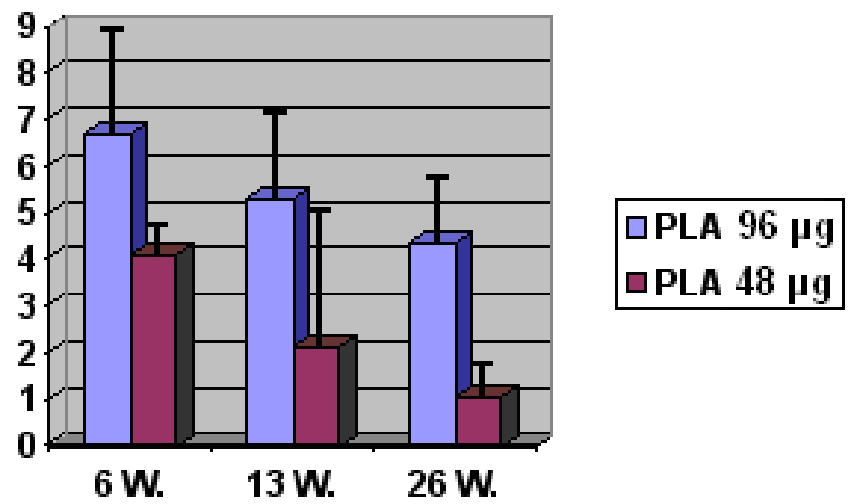

\section{Zeit}




\subsection{Kollagenträger}

\subsubsection{6 $\mu$ g rh-BMP-2}

Die $96 \mu \mathrm{g}$ rh-BMP-2-Konzentrationsgruppe der Kollagenträger zeigte ebenfalls eine deutlich erhöhte Knochenneubildung verglichen mit den Kollagenträgern ohne rh-BMP-2-Zusatz und verglichen mit den reinen Defekt-Kontrollgruppen. Es zeigte sich bei $96 \mu \mathrm{g}$ rh-BMP-2 pro Implantat nach 6 Wochen eine Fläche an neu gebildetem Knochen von 7,43 $\mathrm{mm}^{2}$ und nach 13 Wochen $11,87 \mathrm{~mm}^{2}$. Bei den Kollagenträgern, die keine rh-BMP-2-Beschickung erhalten hatten, betrug die gemessene Fläche nach 6 Wochen $0,98 \mathrm{~mm}^{2}$ und nach 13 Wochen $0,43 \mathrm{~mm}^{2}$.

Sowohl nach 6 als auch nach 13 Wochen wurde damit unter dem Zusatz von der hohen rh-BMP-2-Konzentration signifikant mehr Knochen gebildet als ohne Wachstumsfaktor $(\mathrm{p} \leq 0,001)$.

\section{Knochenneu- bildung in $\mathbf{m m}^{2}$}

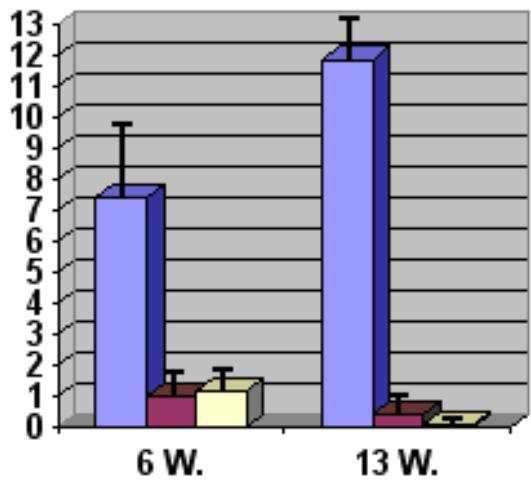

Zeit 
Innerhalb der $96 \mu \mathrm{g}$ rh-BMP-2-Konzentrationsgruppe nahm die gebildete Knochenfläche von der 6-Wochen-Gruppe zur 13-Wochen-Gruppe signifikant zu $(p=0,021)$.

\section{Knochenneu- bildung in $\mathbf{~ m m}^{2}$}

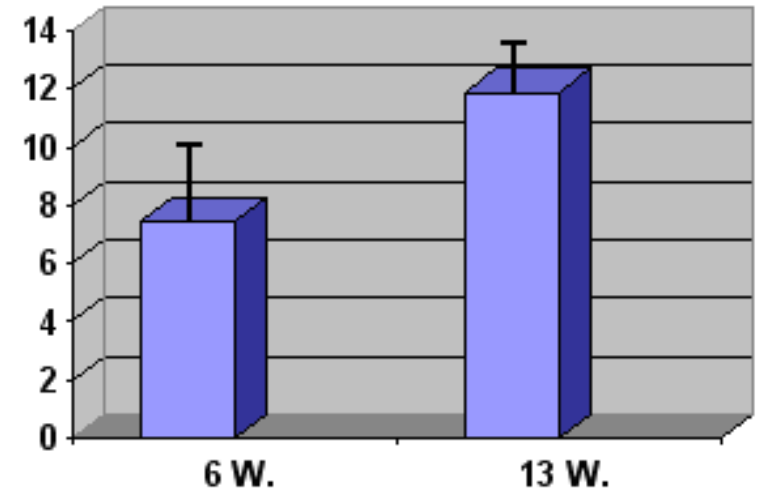

\section{Zeit}

Abb. 23: Kollagenträger der $96 \mu \mathrm{g}$ rh-BMP-2-Konzentration nach 6 und 13 Wochen

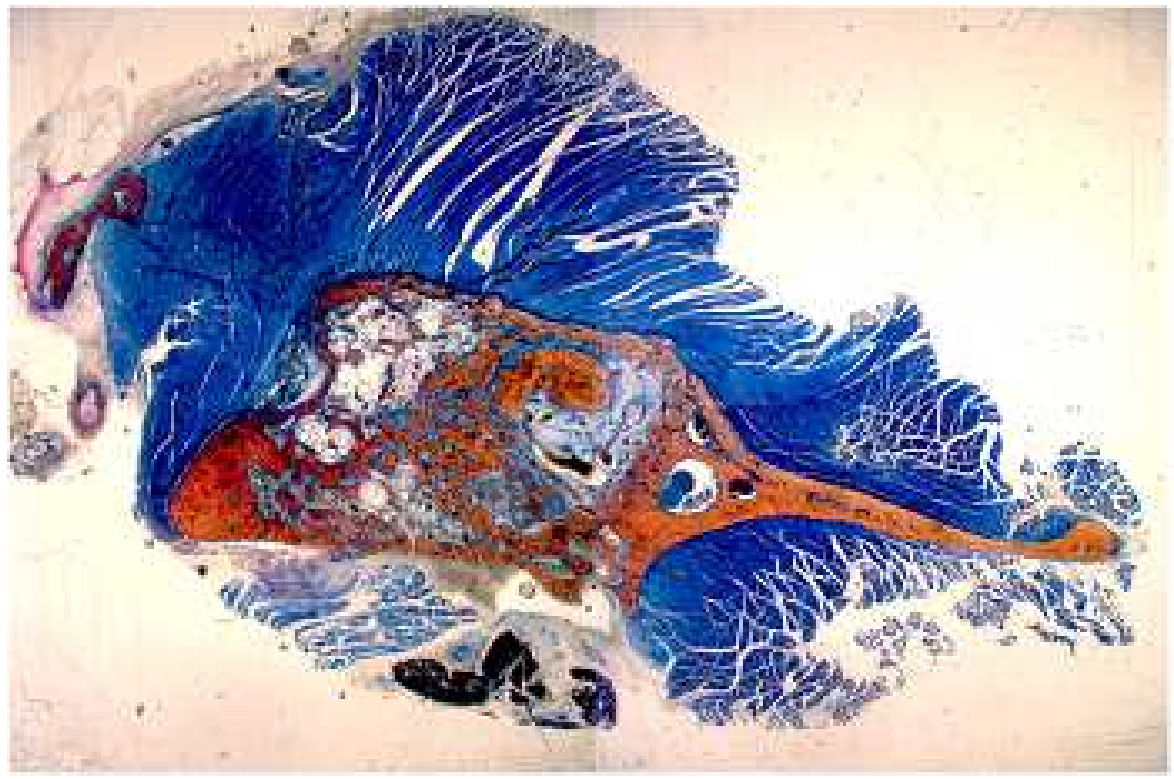

Abb. 24: Kollagen $96 \mu \mathrm{g}$ rh-BMP-2 nach 6 Wochen 


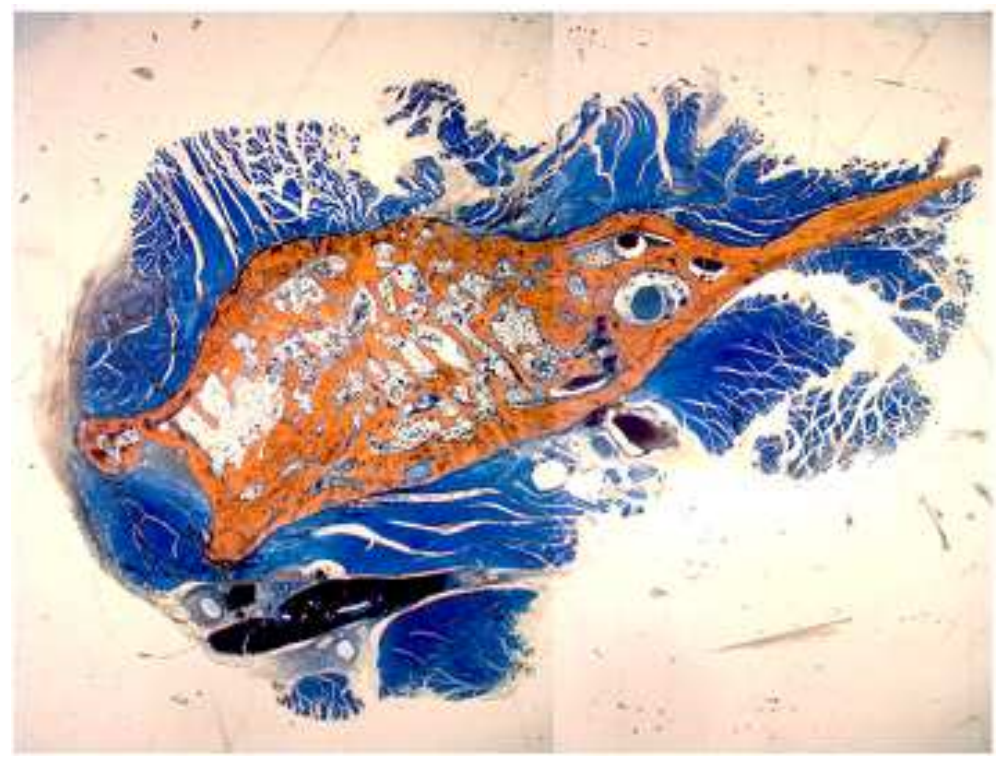

Abb. 25: Kollagen $96 \mu \mathrm{g}$ rh-BMP-2 nach 13 Wochen

\subsection{2 $48 \mu$ g rh-BMP-2}

Die niedrigere rh-BMP-2-Konzentration lieferte bei den Kollagenträgern nach 6 Wochen Ergebnisse von 5,65 $\mathrm{mm}^{2}$ und nach 13 Wochen 5,74 $\mathrm{mm}^{2}$. Sowohl nach 6 als auch nach 13 Wochen wurde damit unter dem Zusatz von der niedrigen rh-BMP-2-Konzentration signifikant mehr Knochen gebildet als ohne Wachstumsfaktor $(\mathrm{p} \leq 0,003)$.

\section{Knochenneu- bildung in $\mathbf{m m}^{2}$}

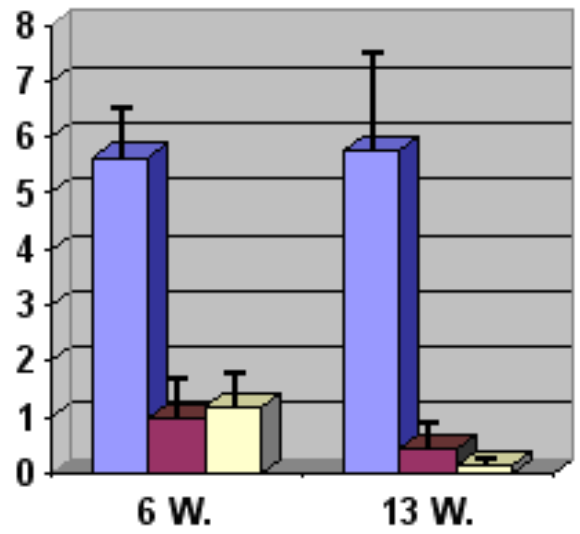

$$
\begin{array}{|l|}
\hline \square \mathrm{KG} 48 \mu \mathrm{g} \\
\square \mathrm{KG} \text { leer } \\
\square \text { Leerdefekt }
\end{array}
$$

\section{Zeit}


Insgesamt nahm die Knochenneubildung von der 6-Wochen-Gruppe zur 13Wochen-Gruppe leicht zu, jedoch nicht signifikant $(\mathrm{p}=0,92)$.

\section{Knochenneu- bildung in $\mathbf{m m}^{2}$}

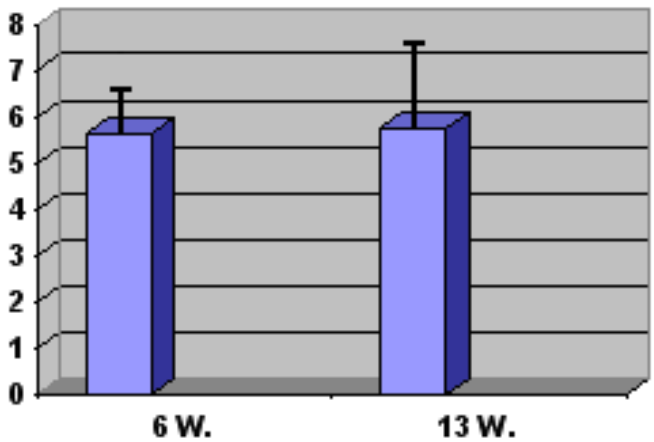

\section{Zeit}

Abb. 27: Kollagenträger der $48 \mu \mathrm{g}$ rh-BMP-2-Konzentration nach 6 und 13 Wochen

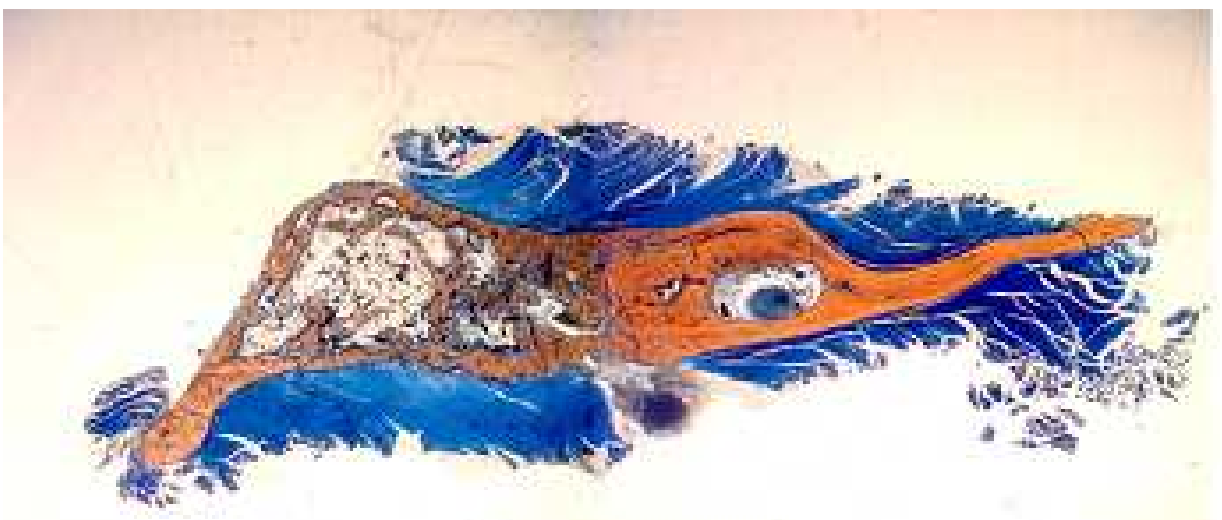

Abb. 28: Kollagen $48 \mu$ g rh-BMP-2 nach 6 Wochen 


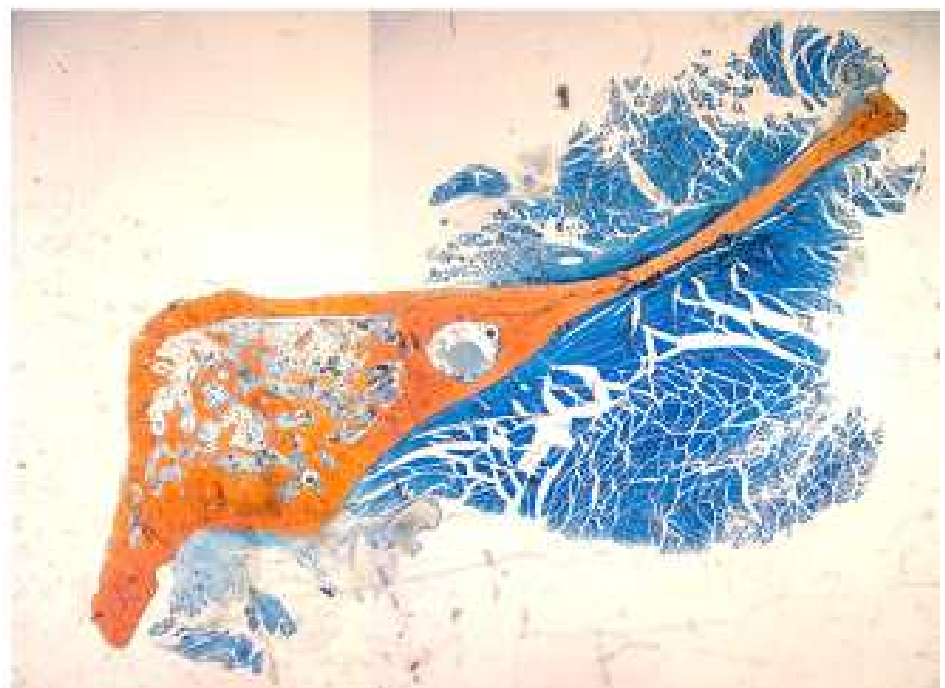

Abb. 29: Kollagen $48 \mu$ g rh-BMP-2 nach 13 Wochen

\subsubsection{Vergleich der $96 \mu \mathrm{g}$ - und der $48 \mu \mathrm{g}$-Konzentration}

Im Vergleich der beiden Konzentrationen führte auch hier die höhere Konzentration zu einer vermehrten Knochenneubildung. Für die 6-WochenGruppe war dieses Ergebnis nicht signifikant $(\mathrm{p}=0,192)$. In der 13-WochenGruppe wurde durch die höhere rh-BMP-2-Konzentration signifikant mehr neuer Knochen gebildet als durch die niedrigere $(p=0,004)$.

\section{Knochenneu- bildung in $\mathbf{m m}^{2}$}

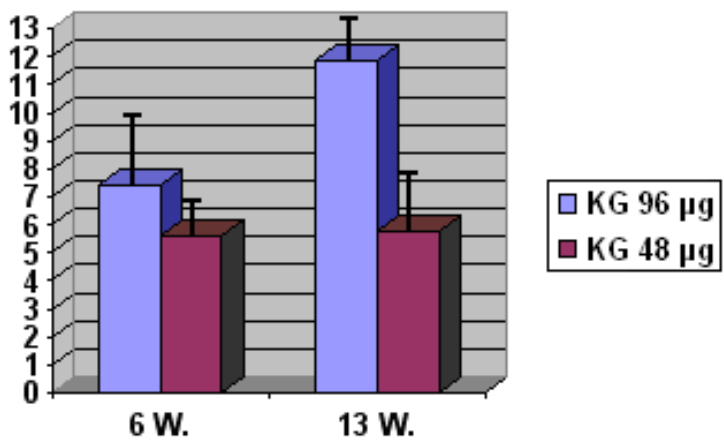

\section{Zeit}




\subsection{Vergleich der Polylaktid- und Kollagenträger}

Sowohl bei der $96 \mu \mathrm{g}$ rh-BMP-2-Konzentration als auch bei der $48 \mu \mathrm{g}$ rh-BMP-2Konzentration kam es nach 6 als auch nach 13 Wochen mit Kollagen als Trägermaterial zu mehr neu gebildetem Knochen als mit den Polylaktidträgern. Dies war signifikant für die hohe Konzentration nach 13 Wochen $(\mathrm{p}<0,001)$ und für die niedrigere Konzentration nach 6 Wochen $(p=0,008)$.

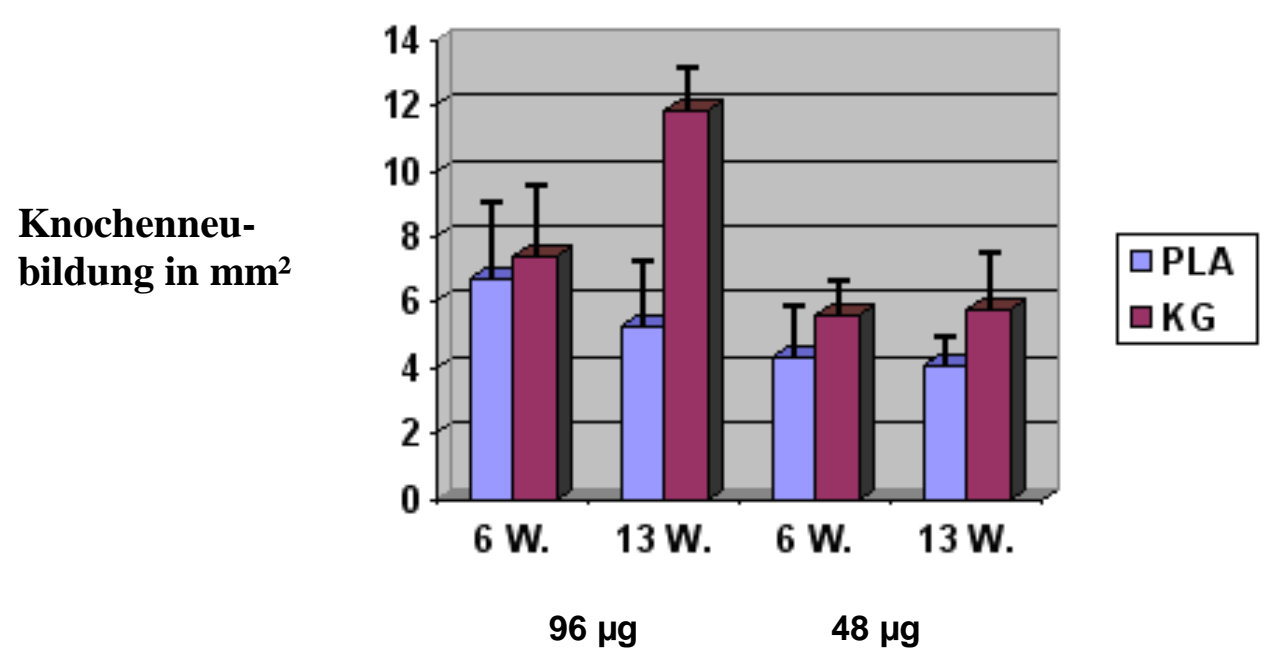

\section{Zeit und Konzentration}

Abb. 31: Polylaktid - und Kollagenträger

Vergleich der Konzentrationen und Zeiten

Eine Übersicht über die absoluten Zahlen, Einzel- und Mittelwerte liefert

Tabelle 3 im Anhang. 
Bei den mit rh-BMP-2 beschickten Präparaten kam es sowohl bei den Polylaktidträgern als auch bei den Kollagenträgern innerhalb der Testzeit zu keiner dichten, kompakten knöchernen Durchbauung der gesetzten Defekte. Die Grenzen der Defekte waren in jedem Präparat zu erkennen. Eine Defektüberbrückung war bei den Polylaktidträgern bei der $96 \mu$ g rh-BMP-2Konzentration nach 6, 13 und 26 Wochen $\mathrm{zu}$ erkennen. Bei der niedrigeren Konzentration an rh-BMP-2 war eine Überbrückung in der 6-Wochen-Gruppe zu verzeichnen. Die Kollagenträger zeigten bei beiden Konzentrationen sowohl nach 6 als auch nach 13 Wochen Defektüberbrückungen. 


\section{DISKUSSION}

\subsection{Interesse an Wachstumsfaktoren}

Große Defekte und komplizierte Frakturen, bei denen keine spontane knöcherne Regeneration zu erwarten ist, stellen Ärzte in der plastischen Chirurgie vor eine schwierige Aufgabe. Mittels Osteosyntheseplatten und autologen Knochentransplantaten wird versucht die Defektregionen zu überbrücken und eine knöcherne Ausheilung anzustreben. Dabei gilt autologer Knochen als sogenannter Goldener Standard, da die Verträglichkeit gegeben und das Infektionsrisiko durch fremde Stoffe und Gewebe nicht vorhanden ist (Kloss et al. 2004, Nkenke et al. 2001, Raghoebar et al. 1996, Rueger JM 1998, Schenk et al. 2000, Schlegel et al. 1998, Schwenzer und Ehrenfeld 2002).

Jedoch sind die begrenzte Verfügbarkeit und die notwendige zusätzliche Entnahmeoperation nachteilige und einschränkende Eigenschaften des autologen Knochentransplantats (Foitzik und Merten 1999, Grob 1989, Rueger JM 1995).

Allogene Transplantate von fremden Individuen oder sogar xenogene Transplantate von anderen Spezies tragen die Gefahr einer Unverträglichkeitsreaktion auf das fremde Gewebe und beinhalten zudem eine Infektionsgefahr des Patienten durch bspw. HIV, Hepatitis oder andere virale Erkrankungen (Gürtler 1994, Hierholzer und Zilch 1980, Lord et al. 1988, Schratt und Spyra 1997, Simmonds et al. 1992).

Andere Materialien wie Titanplatten oder Keramiken enthalten keine lebenden Zellen und haben lediglich eine defektüberbrückende Wirkung und können allenfalls als Knochenleitstruktur (osteokonduktiv) dienen (Urist 1965).

Das Interesse an Wachstumsfaktoren, die das vorhandene Gewebe stimulieren und eine De-novo-Knochensynthese induzieren, wächst daher zunehmend. 
Wachstumsfaktoren wie BMP-2 können mittlerweile synthetisch hergestellt werden, was eine nahezu unbegrenzte Verfügbarkeit ermöglicht.

Zahlreiche Studien und Forschungen haben belegt, dass BMP-2 als einer der wenigen Wachstumsfaktoren allein in der Lage ist eine Neusynthese von Knochen zu stimulieren, sogar im Muskelgewebe (Reddi 2000b, Urist 1965, Urist et al. 1979, Valentin-Opran et al. 2002).

Die Frage stellt sich nach der Gabe einer geeigneten therapeutischen Konzentration des Wachstumsfaktors, da in Versuchen eine vielfach höhere Konzentration verwendet wird als üblicherweise im Körper vorkommt (Tschakaloff et al. 2000).

Es sollte eine genügend hohe Konzentration verwendet werden, um die gewünschten Effekte zu erzielen, jedoch nicht überflüssig hoch, um keine unerwünschten Nebeneffekte wie überschießendes Knochenwachstum zu erzeugen.

In dieser Studie wurden zwei Konzentrationen getestet und ihre Auswirkungen auf das Knochenwachstum über verschieden lange Zeiträume gemessen.

\subsection{Einfluss des Implantatlagers auf die Wirksamkeit der BMPs}

Neben der Art des Trägermaterials oder dem Ort des Defekts hat auch das Implantatlager Einfluss auf die Wirksamkeit der BMPs. Zwar induziert BMP-2 sowohl im orthotopen Gewebe als auch im ektopen Gewebe (z.B. Muskelgewebe) die Knochenneubildung, trotzdem hat das Implantatlager Einfluss auf die Knochenneubildung durch BMPs.

Dies erkennt man daran, dass beispielsweise BMPs in der Nähe von Periost viel schneller Knochenwachstum induzieren als im ektopen Gewebe, wo die typischen Zellen der Knochenregeneration zunächst nicht oder nur spärlich vorhanden sind. 
Die Kochenhaut, das Periost, ist gut durchblutet und besitzt eine hohe regenerative Potenz, da es zahlreiche Vorläuferzellen der Knochenbildung enthält und daher Zielzellen der BMPs wie Osteoprogenitorzellen und Osteoblasten bereits vorhanden sind (Hanada et al. 2001, Würzler et al. 2000).

Im Muskelgewebe muss dagegen zunächst eine Rekrutierung bzw. Umwandlung von Mesenchymzellen in knochenbildende Zellen erfolgen (Levander 1938, Oka et al. 2007, Owen 1970, Reddi 2000b, Reddi 2000c, Rueger DC 2002).

Ein starkes Implantatlager mit gut vaskularisiertem Weichgewebe erleichtert den BMPs ihre Aufgabe. Dass es im ektopen Gewebe - wenn auch langsamer dennoch zu einer Knochenbildung kommt, zeigt die starke osteoinduktive Potenz der BMPs.

\subsection{Geeignete Trägermodelle}

Neben der Konzentration kommt dem Trägermaterial eine bedeutende Stellung zu. Trägermaterialien können die osteoinduktive Wirkung der Wachstumsfaktoren verstärken und sorgen dafür, dass die Faktoren konzentriert an einen Ort eingebracht und anschließend freigesetzt werden können (Sakou 1998).

Dabei beweisen sowohl anorganische als auch organische resorbierbare Materialien ihre verstärkenden osteoinduktiven Eigenschaften (Bouxsein et al. 2001, Gao et al. 1993, Kawamura und Urist 1988, Lee et al. 1999, Winn et al. 1999).

Zahlreiche Studien haben sich mit der Heilung von Knochendefekten auseinandergesetzt und dabei die verschiedensten Carrier, Wachstumsfaktoren und Spezies untersucht. So untersuchten Arosarena und Collins (2005a) ebenfalls im Ratten-Unterkiefermodell - ein Hyaluronsäurepolymer und einen Carrier-Komplex aus Kollagen, Kalziumphosphat und Trikalziumphosphat und verzeichneten dabei leichte Vorteile für die Knochenheilung bei Verwendung des Hyaluronsäurepolymers. 
Bei einem Vergleich von rh-BMP-2 und rh-BMP-4 im gleichen Jahr - ebenfalls im Rattenmodell - beobachteten Arosarena und Collins, dass eine Defektüberbrückung eher unter Gabe von rh-BMP-2 erreicht werden konnte. Roldan et al. konnten 2004 Unterkieferaugmentationen unter dem positiven Einfluss von rh-BMP-7 verzeichnen. Ein PGS-Carrier (Polylactid-Co-GlycolicAcid/ Gelatin-Sponge) in Kombination mit rh-BMP-2 wurde sowohl 1999 von Higuchi et al. bei Rattenunterkiefern, als auch 2002 von Nagao et al. bei critical size defects im Hundeunterkiefer als funktionierendes Konzept für eine beschleunigte Knochenheilung vorgestellt. Marakuwa et al. 2001 und Boyne et al. 2006 wiesen nach, dass rh-BMP-2 auch bei Primaten zu den gewünschten Effekten führt und zogen daraus Rückschlüsse auf Modelle für den Menschen.

In all diesen Studien wurden positive Effekte der BMPs auf die Knochenheilung mit ihren jeweiligen Trägermaterialien verzeichnet.

Ein Problem ist jedoch die Freisetzungskinetik der Wachstumsfaktoren aus den Trägermaterialien. Die Carrier in diesen Studien waren lediglich mit den Wachstumsfaktoren getränkt worden, woraus eine schnelle Freisetzung der Wachstumsfaktoren von 80-90 \% innerhalb der ersten 24-48 Stunden resultierte (Uludag et al. 2000).

Dies führte zwar zu einer Knochenbildung, allerdings konnte keine Freisetzungskinetik der Wachstumsfaktoren für diese Trägermaterialien angegeben werden. In der vorliegenden Studie wurde für die Polylaktidträger eine Beladungsmethode verwendet, die Schliephake et al. 2007 in einer In-vitro-Studie veröffentlichten. Hier war es gelungen, eine definierte Menge des Wachstumsfaktors rh-BMP-2 durch Begasung unter hohem $\mathrm{CO}_{2}$-Druck in Polylaktidträger einzuschließen und anschließend über einen Zeitraum von 27 Tagen in Abständen die freigesetzte Menge des Wachstumsfaktors zu messen. Die fehlenden Daten zur Freisetzungskinetik der anderen Studien so wie die unterschiedlichen Konzentrationen und die Verwendung unterschiedlicher Materialien machen es schwer die Ergebnisse dieser Studie mit denen der anderen zu vergleichen. 
Im Grundsatz decken sich jedoch die Aussagen der Studien mit dieser darin, dass mit BMPs und geeigneten Trägermodellen eine beschleunigte Knochenheilung erreicht werden kann. Des Weiteren ist die Knochenregeneration in dieser Studie über einen wesentlich längeren Zeitraum verfolgt worden. Die meisten anderen Studien hatten Beobachtungsintervalle von 4, 8 oder maximal 12 Wochen. In dieser Arbeit wurden Untersuchungen bis zur 26. Woche vorgenommen. Es zeigte sich dabei, dass auch nach einer längeren Zeitspanne bei genügend hoher Konzentration an Wachstumsfaktor noch Knochenneubildung statt fand.

Eigenschaften wie Ladung, Porengröße und Oberflächenbeschaffenheit der Carrier haben ebenso Einfluss auf die Knochenentstehung und sollten in weiteren Studien noch genauer erforscht werden, um optimale Charakteristika für einen Carrier benennen zu können (Bostrom et al. 1998, Boyan et al. 1999, Friedländer et al. 2001, Gao et al. 1993, Hollinger et al. 1998, Itoh et al. 1998, Kawamura und Urist 1988, Kirker-Head 1995, Kuboki et al. 1998, Ruppert et al. 1996, Schwartz et al. 1998, Winn et al. 1998, Winn et al. 1999).

\subsection{Polylaktid als Carrier}

Das hier verwendete Polylaktid ist ein Polymer der D- und L-Milchsäure. Polymere lassen sich im Körper restlos abbauen. Durch Hydrolyse wird das Laktid zur Milchsäure degradiert, ein natürliches Molekül, welches vom Körper weiter zerlegt und letztlich als Kohlendioxid und Wasser ausgeschieden wird (Kulkarni et al. 1966, Laurencin und Lane 1994).

Da Polymere synthetisch hergestellt werden können, lassen sich die Kosten niedrig halten und die Infektionsgefahr gering. Einige Studien weisen auf erhöhte Zahlen von Entzündungszellen wie Makrophagen, mehrkernigen Riesenzellen und Lymphozyten um Implantate aus Polymer hin. 
Dies konnte jedoch in anderen Studien und auch in dieser nicht bestätigt werden (Miki et al. 1994, Winn et al. 1999, Zegzula et al. 1997).

Getestet wurden in dieser Studie zwei verschiedene rh-BMP-2-Konzentrationen, 96 - bzw. $48 \mu \mathrm{g}$ rh-BMP-2 pro Implantat. Im Vergleich der beiden Konzentrationen kam es bei der höheren Konzentration zu einer signifikant erhöhten Knochenbildung und zur Überbrückung der Defekte. Eine höhere Dosis rh-BMP-2 bewirkt demnach ein erhöhtes Maß an Knochenneubildung. Sowohl die hohe rh-BMP-2-Konzentration mit $96 \mu \mathrm{g}$ als auch die niedrigere mit $48 \mu \mathrm{g}$ wiesen gegenüber den Versuchstieren, die Polylaktidträger ohne Zusatz von BMP erhalten hatten, und gegenüber den reinen Leerdefekten signifikant erhöhte Knochenbildungen auf, was die osteoinduktive Wirksamkeit des Wachstumsfaktors verdeutlicht. Diese Beobachtungen decken sich mit denen, die Zegzula et al. 1997 bei critical size defects im Kaninchenmodell machen konnten oder Winn et al. 1999 im ektopen Rattenmodell.

Zwischen den unbeschichteten Trägern und den reinen Leerdefekten war ebenfalls teilweise ein signifikant erhöhter Knochenaufbau zu beobachten, was auf einen positiven Effekt des Carriers als Knochenleitstruktur schließen lässt.

Auffallend war die Abnahme der gemessenen Knochenfläche über die Zeit. Erklären lässt sich diese Beobachtung zum Einen mit einem am Anfang erhöhten Knochenaufbau, der übergeht in Remodelingprozesse, die einen stabileren Knochen herbeiführen sollen und in deren Rahmen auch Knochenabbau betrieben wird (Schwenzer und Ehrenfeld 2002). Des Weiteren entsteht im Rahmen der Degradation des Polylaktids durch Hydrolyse Milchsäure, die den periimplantären pH absenkt (Kulkarni et al. 1966, Laurencin und Lane 1994). Zwar kann Milchsäure vom Körper weiter zerlegt werden, wenn sie jedoch konzentriert vorkommt, wie im Umfeld des Trägermaterials, scheint sie zu einem Abfall des $\mathrm{pH}-$ Wertes des umliegenden Gewebes zu führen und so einen negativen Einfluss auf die Knochenproduktion $\mathrm{zu}$ haben. Es ist anzunehmen, dass ein Zusammenwirken der genannten Faktoren zu den vorliegenden Ergebnissen führt. 
Der pH-Abfall konnte bereits in einer In-vitro-Studie beobachtet werden, in der die Polylaktidträger untersucht wurden (Schliephake et al. 2007, Abfall des pHWertes von 7 auf 3). Während die hohe rh-BMP-2-Konzentration diesem Effekt entgegenwirken kann und nur ein geringer Rückgang an Knochenneubildung über die Zeit zu verzeichnen ist, sind die Auswirkungen bei der niedrigeren rh-BMP-2Konzentration schon deutlicher zu sehen, da sich die Messergebnisse der Knochenneubildung hier halbieren und die 13- und 26-Wochen-Gruppen keine Defektüberbrückung mehr zeigen. Ziel weiterer Studien muss es sein, hier geeignete Puffer und neutralisierende Gegenspieler zu entwickeln, die dem Trägermaterial zugesetzt werden und diesen unerwünschten Effekt abfangen können. In Frage kämen hier z. B. Substanzen wie Kalziumkarbonate oder Kalziumphosphate (Schiller et al. 2004).

Die Ergebnisse der Polylaktidimplantate zeigen, dass sie prinzipiell geeignet sind, Wachstumsfaktoren kontrolliert freizusetzen und so Knochenwachstums über einen längeren Zeitraum zu induzieren und Defekte kritischer Größe zu überbrücken.

\subsection{Kollagen als Carrier}

Das hier verwendete Kollagen ist equinen Ursprungs (Pferdesehnen). Ein Infektionsrisiko durch beispielsweise TSE (Transmissible Spongiforme Encephalopathie) wird vom Hersteller jedoch ausgeschlossen (Kollagen Resorb, Resorba CliniCare ${ }^{\circledR}$, Nürnberg). Die Verfügbarkeit ist erheblich höher als bei autologen Transplantaten, bei denen zudem Zweitoperationen notwendig sind (Schwenzer und Ehrenfeld 2002). Da Kollagen ein natürliches körpereigenes Gewebe ist, wird es rasch und problemlos enzymatisch abgebaut. In Studien hat sich ein gesteigerter Abbau des Kollagens bei seiner Verwendung mit BMPs gezeigt, so dass der Carrier nach ein paar Wochen meist vollständig resorbiert war (Gao et al. 1993, Gordh et al. 1999, Resorba Clinacare ${ }^{\circledR}$ ). 
Weitere Vorteile dieses Präparates sind seine gute Formbarkeit und Handhabe für den Operateur. Da Kollagen ein äußerst weiches Material ist, eignet es sich nicht zur Stabilisierung von größeren Defekten (Horisaka et al. 1994, Riedel und Valentin-Opran 1999).

Getestet wurden auch mit diesem Carrier die beiden rh-BMP-2-Konzentrationen von 96 - bzw. $48 \mu \mathrm{g}$ pro Implantat, um die Osteoinduktivität des Wachstumsfaktors nachzuweisen. Im Vergleich der beiden Konzentrationen lieferte die höhere Konzentration nach 13 Wochen signifikant höhere Messergebnisse für den neu entstandenen Knochen. Verglichen mit den unbeschickten Kollagenträgern und mit den reinen Leerdefekten wiesen die mit rh-BMP-2 beschickten Proben stets eine signifikant höhere Ossifikation auf, was auch in Kombination mit Kollagen die osteoinduktive Potenz des Wachstumsfaktors rh-BMP-2 zeigt. Auch bei den Kollagenträgern konnte eine Defektüberbrückung verzeichnet werden, dies deckt sich mit den Beobachtungen, die Hollinger et al. 1998 im Kaninchenmodell gemacht haben.

Bei den beiden Konzentrationen mit Kollagen als Carrier ist ein deutlicher Anstieg an neuem Knochen über die Zeit zu verzeichnen. Während dies bei der geringeren Konzentration eher schwach ausfällt, ist bei der hohen rh-BMP-2Konzentration ein signifikanter Anstieg des Knochenaufbaus über die Zeit zu beobachten. 26-Wochen-Gruppen gab es bei den Kollagenträgern nicht. Es wäre interessant gewesen, wie sich der Knochenaufbau bei der hohen rh-BMP-2Konzentration bei diesem Trägermaterial entwickelt hätte, d.h. ob es zu einem weiteren Anstieg gekommen wäre oder ob die Knochenmenge gleich geblieben oder sogar ein Rückgang zu beobachten gewesen wäre.

Die Ergebnisse dieser Studie sprechen für die guten Eigenschaften des Kollagens als Trägermaterial. Es lässt durch seine rasche Resorption und lockere Struktur ein schnelles Einwachsen neuen Knochens zu. Die lockere Struktur erleichtert ebenso die Angiogenese, was wiederum fördernd für den Knochenaufbau ist. Allerdings haben Kollagene als Trägermaterialien weder formgebende noch stabilisierende Einflüsse auf die Defekte und das Knochenwachstum. 


\subsection{Vergleich der beiden Carrier}

Vergleicht man die beiden Carrier - die Polylaktid- und Kollagenträger untereinander, fällt auf, dass bei beiden Trägermaterialien eine höhere rh-BMP-2Konzentration auch zu einer erhöhten Knochenneubildung führt.

Die Kombination von Kollagen mit rh-BMP-2 führt jedoch in beiden Konzentrationen und sowohl nach 6, als auch nach 13 Wochen zu mehr neuer Knochenmasse als die Kombination von Polylaktidträgern mit rh-BMP-2.

Diese Beobachtung ist zunächst erstaunlich, da die Kollagenträger lediglich mit dem Wachstumsfaktor beträufelt worden waren und daraus eine schnelle Freisetzung mit einer anfänglichen hohen Antwort des Knochenaufbaus erwartet worden wäre. Jedoch zeigen die Kollagenträger gerade nach einer längeren Zeitspanne von 13 Wochen unter der hohen rh-BMP-2-Konzentration eine enorme Knochenneubildung.

Da sonstige Parameter wie der Ort des Defektes (Mandibula), die getestete Zeitspanne, die Spezies (männliche Wistar-Kyoto-Ratten) und die BMPKonzentrationen und Art (rekombinant hergestelltes rh-BMP-2) für beide Träger gleich waren, ist dieser positive Effekt der vermehrten Knochenbildung zum Einen den Eigenschaften des Kollagens als Trägermaterial zuzuschreiben.

Gründe könnten die lockere Struktur des Materials sein, die eine gute und rasche Angiogenese zulässt und ein Einwachsen des Knochens erleichtert und die rasche Resorption, die ein schnelles und gutes Ersetzen des Carriers durch Knochen ermöglicht. Zum Anderen kommt bei den Polylaktidträgern der erwähnte pHAbfall des umliegenden Gewebes zum Tragen, so dass sie im Vergleich mit den Kollagenträgern geringere Werte der Knochenneubildung erzielen.

Mit geeigneten neutralisierenden Substanzen ist dieser unerwünschte Effekt bei den Polylaktidträgern in Zukunft möglicherweise zu mindern. 
Für stabilisierende Auswirkungen auf den Defekt ist Kollagen ein zu weiches Material. Hier zeigen sich die Vorteile der Polylaktidimplantate. Sie können den Defekt stabilisieren und lassen sich zudem in der gewünschten Form herstellen, so dass für die Zukunft defektbezogene, individuell hergestellte Implantate beispielsweise nach Tumorresektion - vorstellbar sind.

Die optimale Konzentration und Menge an Wachstumsfaktor - in Verbindung mit dem optimalen Trägermaterial für die jeweilige Situation - herauszufinden und diese anschließend in klinischen Studien am Patienten noch genauer $\mathrm{zu}$ untersuchen, wird die zukünftige Aufgabe auf diesem Forschungsgebiet sein (Boden 1999, Geesink et al. 1999). 


\section{ZUSAMMENFASSUNG}

Wachstumsfaktoren - wie BMP-2 - stehen auf Grund ihrer osteoinduktiven Potenz schon länger im Interesse der Wissenschaft. Die Frage stellt sich nach geeigneten Trägermaterialien und der optimalen Konzentration der Wachstumsfaktoren für eine beschleunigte Frakturheilung.

Dazu wurden in dieser Arbeit zwei verschiedene Materialien hinsichtlich ihrer Eignung als Trägermaterial und Auswirkung auf die Knochenheilung gestestet: ein Polylaktid und ein Kollagen equinen Ursprungs.

Diese zwei Trägermaterialien wurden jeweils mit zwei Konzentrationen rekombinant in E.coli hergestellten rh-BMP-2s beschickt (96 - bzw. $48 \mu \mathrm{g}$ rhBMP-2 pro Implantat) und in die Kieferwinkel 45 männlicher Wistar-KyotoRatten implantiert. Hierzu wurden $5 \mathrm{~mm}$ große Defekte kritischer Größe gesetzt und die jeweiligen Träger und Konzentrationen für unterschiedlich lange Zeiträume (6, 13 und 26 Wochen) eingebracht.

Im Anschluss daran wurden Feinschliffpräparate erstellt, gefärbt und unter dem Mikroskop begutachtet. Der neu entstandene Knochen wurde definiert und mittels eines speziellen Computerprogramms gemessen.

Im Ergebnis führte dabei die höhere rh-BMP-2-Konzentration bei beiden Trägermaterialien zu einem vermehrten Ausmaß an Knochenneubildung als die niedrigere und es kam zu einer Überbrückung der kritischen Defekte, was die osteoinduktive Potenz des rh-BMP-2 verdeutlicht.

Im Vergleich der beiden Carrier untereinander zeigte sich, dass mit Kollagen als Trägermaterial mehr neuer Knochen aufgebaut wurde als in Kombination mit den Polylaktidträgern als Carrier. Dies könnte an dem beobachteten pH-Abfall im periimplantären Gebiet der Polylaktidträger liegen. Hier besteht weiterer Forschungsbedarf an neutralisierenden Substanzen. 
Hinweise auf überschießendes Knochenwachstum oder Entzündungsreaktionen auf die eingebrachten Materialien gab es in der vorliegenden Arbeit nicht.

Diese Studie hat gezeigt, dass präformierte Polylaktidträger in Kombination mit einer genügend hohen Konzentration an rh-BMP-2 zu einer signifikanten Steigerung der Knochenregeneration im Rahmen der Frakturheilung und zur Überbrückung kritischer Defekte führen. 


\section{ANHANG}

\subsection{Vorabveröffentlichungen}

Teilergebnisse des experimentellen Bestandteils dieser Doktorarbeit wurden bereits veröffentlicht unter:

Schliephake H, Weich HA, Dullin C, Gruber R, Frase S (2008) :

Mandibular bone repair by implantation of rhBMP-2 in a slow release carrier of polylactic acid - an experimental study in rats

Biomaterials 29, 103-110 


\subsection{Abkürzungsverzeichnis}

\begin{tabular}{|c|c|}
\hline Abb. & Abbildung \\
\hline Aqua dest. & destilliertes Wasser \\
\hline BMP & Bone Morphogenetic Protein \\
\hline bspw. & beispielsweise \\
\hline bzw. & beziehungsweise \\
\hline ca. & circa \\
\hline $\mathrm{CO}_{2}$ & Kohlenstoffdioxid \\
\hline d.h. & das heißt \\
\hline E. coli & Bakterium Escherichia coli \\
\hline ggf. & gegebenenfalls \\
\hline $\mathrm{kg}$ & Kilogramm \\
\hline $\mathrm{KG}$ & Kollagen(träger) bzw. Körpergewicht \\
\hline li & links \\
\hline $\mathrm{mg}$ & Milligramm \\
\hline $\mathrm{ml}$ & Milliliter \\
\hline $\mathrm{mm}$ & Millimeter \\
\hline$\mu \mathrm{g}$ & Mikrogramm \\
\hline$\mu \mathrm{m}$ & Mikrometer \\
\hline PLA & Polylaktid(träger) \\
\hline re & rechts \\
\hline \multirow[t]{2}{*}{ rh-BMP-2 } & rekombinant hergestelltes \\
\hline & Bone Morphogenetic Protein 2 \\
\hline Tab. & Tabelle \\
\hline u.a. & unter anderem \\
\hline UK & Unterkiefer \\
\hline v.a. & vor allem \\
\hline W & Wochen \\
\hline
\end{tabular}




\subsection{Tabelle 3 - Ergebnisse}

BMP Ergebnisse (in microm²)

\section{UK rechts}

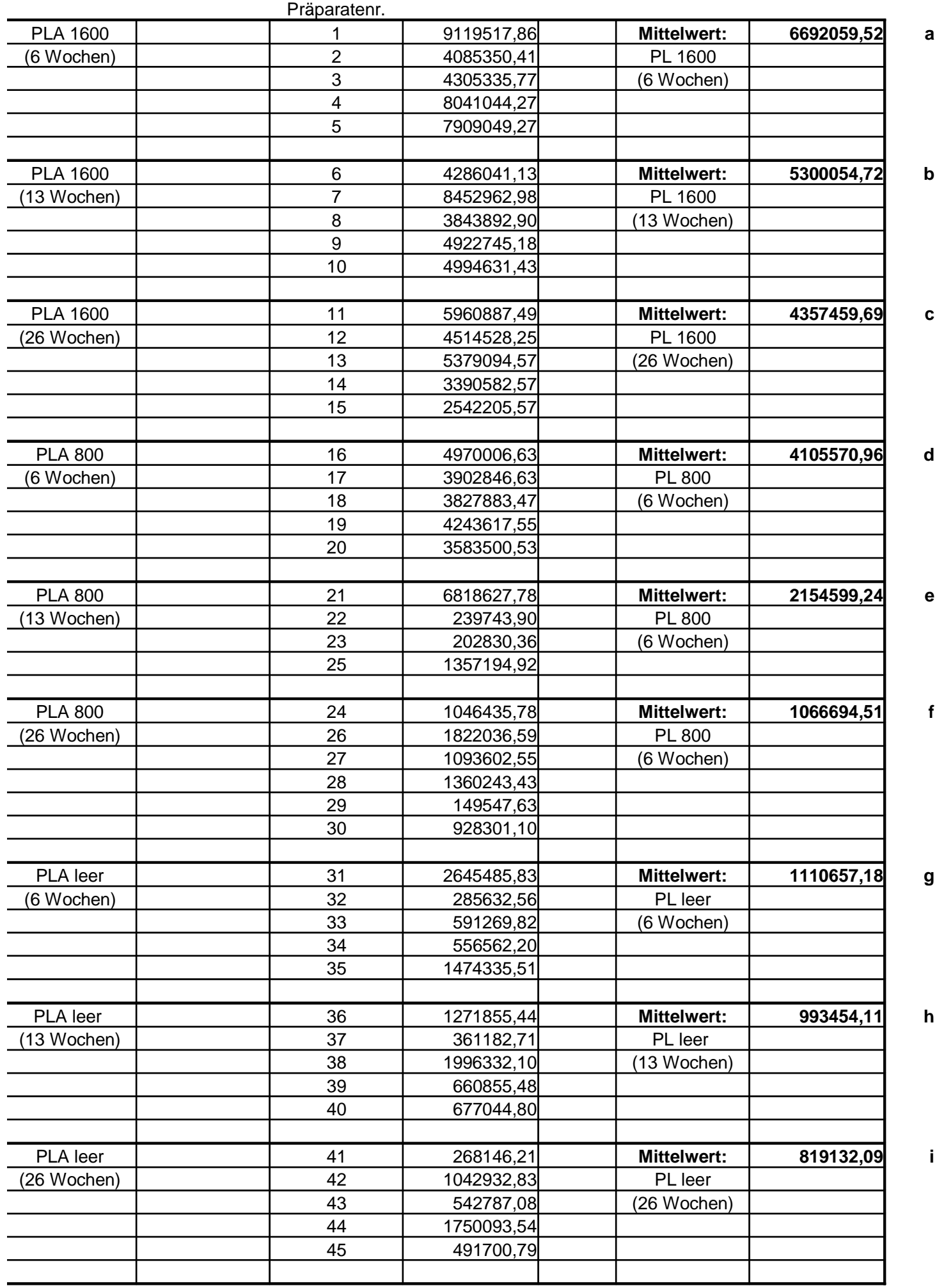


BMP Ergebnisse (in microm²)

\section{UK links}

\begin{tabular}{|c|c|c|c|c|c|c|}
\hline KG 96 & & 1 & 9201704.67 & & Mittelwert & 7427118,87 \\
\hline \multirow[t]{2}{*}{ (6 Wochen) } & & 2 & 4826489,76 & & KR 1600 & \\
\hline & & 3 & 8253162,19 & & (6 Wochen) & \\
\hline & & & & & & \\
\hline KG 96 & & 6 & 12711785,23 & & Mittelwert & 11867605,46 \\
\hline \multirow[t]{2}{*}{ (13 Wochen) } & & 7 & 12313480,70 & & KR 1600 & \\
\hline & & 8 & 10577550,44 & & (13 Wochen) & \\
\hline & & & & & & \\
\hline KG 48 & & 16 & 6503428,41 & & Mittelwert & 5633916,94 \\
\hline \multirow[t]{2}{*}{ (6 Wochen) } & & 17 & 5408632,97 & & KR 800 & \\
\hline & & 18 & 4989689,43 & & (6 Wochen) & \\
\hline & & & & & & \\
\hline KG 800 & & 21 & 7083564,53 & & Mittelwert & 5736032,71 \\
\hline \multirow[t]{2}{*}{ (13 Wochen) } & & 22 & 3619599,86 & & KR 800 & \\
\hline & & 23 & 6504933,74 & & (13 Wochen) & \\
\hline & & & & & & \\
\hline KG leer & & 31 & 1418657,52 & & Mittelwert & 976605,86 \\
\hline \multirow{4}{*}{ (6 Wochen) } & & 32 & 1027623,98 & & KR leer & \\
\hline & & 33 & 432150,61 & & (6 Wochen) & \\
\hline & & 34 & 1510624,20 & & & \\
\hline & & 35 & 493972,98 & & & \\
\hline & & & & & & \\
\hline KG leer & & 36 & 663430,63 & & Mittelwert & 427888,38 \\
\hline \multirow[t]{5}{*}{ (13 Wochen) } & & 37 & 644240,13 & & KR leer & \\
\hline & & 38 & 29197,57 & & (13 Wochen) & \\
\hline & & 39 & 636798,73 & & & \\
\hline & & 40 & 165774,82 & & & \\
\hline & & & & & & \\
\hline eer & & 4 & 534275,85 & & Mittelwert & 1183860,35 \\
\hline \multirow{3}{*}{ (6 Wochen) } & & 5 & 972050,13 & & leer & \\
\hline & & 19 & 1667793,11 & & (6 Wochen) & \\
\hline & & 20 & 1561322,32 & & & \\
\hline & & & & & & \\
\hline leer & & 9 & 79488,60 & & Mittelwert & 116828,17 \\
\hline \multirow{2}{*}{ (13 Wochen) } & & 10 & 194820,91 & & leer & \\
\hline & & 25 & 76175,00 & & (13 Wochen) & \\
\hline & & & & & & \\
\hline eer & & 11 & 244610,16 & & Mittelwert & 217736,84 \\
\hline \multirow[t]{16}{*}{ (26 Wochen) } & & 12 & 228382,98 & & leer & \\
\hline & & 13 & 1341119,21 & & (26 Wochen) & \\
\hline & & 14 & 61793,96 & & & \\
\hline & & 15 & 185523,89 & & & \\
\hline & & 24 & 103242,40 & & & \\
\hline & & 26 & 59900,47 & & & \\
\hline & & 27 & 207204,32 & & & \\
\hline & & 28 & 70390,39 & & & \\
\hline & & 29 & 241665,79 & & & \\
\hline & & 30 & 246939,15 & & & \\
\hline & & 41 & 238778,22 & & & \\
\hline & & 42 & 174589,00 & & & \\
\hline & & 43 & 0,00 & & & \\
\hline & & 44 & 79649,54 & & & \\
\hline & & 45 & 0,00 & & & \\
\hline & & & & & & \\
\hline
\end{tabular}




\title{
6.4 Signifikanzen
}

\author{
Signifikanz nach t-Test
}

\begin{tabular}{|c|c|c|c|c|c|}
\hline $\mathrm{a}$ & 2427458,34 & 5892554011855,22 & 21684760542744,20 & a zu b nicht signifikant & 0,273 \\
\hline & $-2606709,11$ & $6,79493 \mathrm{E}+12$ & $4,33695 \mathrm{E}+12$ & a zu c nicht signifikant & 0,064 \\
\hline & $-2386723,75$ & $5,69645 \mathrm{E}+12$ & 2082535,02 & a zu d signifikant & 0,027 \\
\hline & 1348984,75 & $1,81976 \mathrm{E}+12$ & & a zu g sehr signifikant & $<0.001$ \\
\hline & 1216989,75 & $1,48106 \mathrm{E}+12$ & & a zu aa nicht signifikant & 0,636 \\
\hline & & & & a zu xx sehr signifikant & 0,001 \\
\hline \multirow[t]{6}{*}{$\mathrm{b}$} & $-1014013,59$ & $1,02822 \mathrm{E}+12$ & 13325107177756,10 & b zu a nicht signifikant & 0,273 \\
\hline & 3152908,26 & $9,94083 \mathrm{E}+12$ & $2,66502 \mathrm{E}+12$ & b zu c nicht signifikant & 0,336 \\
\hline & $-1456161,82$ & $2,12041 \mathrm{E}+12$ & 1632489,337 & b zu e nicht signifikant & 0,068 \\
\hline & |-377309,54 & $1,42362 \mathrm{E}+11$ & & b zu h sehr signifikant & $<0.001$ \\
\hline & $-305423,29$ & 93283388518 & & b zu bb sehr signifikant & $<0.001$ \\
\hline & & & & b zu yy sehr signifikant & 0,002 \\
\hline \multirow[t]{6}{*}{ c } & 1603427,80 & $2,57098 \mathrm{E}+12$ & $7,86939 \mathrm{E}+12$ & c zu a nicht signifikant & 0,064 \\
\hline & 157068,56 & 24670532540 & $1,57388 \mathrm{E}+12$ & c zu b nicht signifikant & 0,336 \\
\hline & 1021634,88 & $1,04374 \mathrm{E}+12$ & 1254542,782 & c zu f sehr signifikant & $<0.001$ \\
\hline & $-966877,12$ & $9,34851 \mathrm{E}+11$ & & c zu i sehr signifikant & $<0.001$ \\
\hline & $-1815254,12$ & $3,29515 \mathrm{E}+12$ & & c zu zz sehr signifikant & $<0.001$ \\
\hline & & & & & \\
\hline \multirow[t]{6}{*}{ d } & 864435,67 & $7,47249 \mathrm{E}+11$ & $1,15707 \mathrm{E}+12$ & d zu a signifikant & 0,027 \\
\hline & $-202724,33$ & 41097154785 & $2,31414 \mathrm{E}+11$ & d zu e nicht signifikant & 0,155 \\
\hline & $-277687,49$ & 77110343213 & 481055,2813 & d zu f sehr signifikant & $<0.001$ \\
\hline & 138046,59 & 19056860458 & & d zu g sehr signifikant & $<0.001$ \\
\hline & $-522070,43$ & $2,72558 \mathrm{E}+11$ & & d zu cc sehr signifikant & 0,008 \\
\hline & & & & d zu xx sehr signifikant & $<0.001$ \\
\hline \multirow[t]{5}{*}{$\mathrm{e}$} & 4664028,54 & $2,17532 \mathrm{E}+13$ & $2,98651 \mathrm{E}+13$ & e zu b nicht signifikant & 0,068 \\
\hline & $-1914855,34$ & $3,66667 \mathrm{E}+12$ & $7,46627 \mathrm{E}+12$ & e zu d nicht signifikant & 0,155 \\
\hline & $-1951768,88$ & $3,8094 \mathrm{E}+12$ & 2732448,014 & e zu f nicht signifikant & 0,356 \\
\hline & $-797404,32$ & $6,35854 \mathrm{E}+11$ & & e zu h nicht signifikant & 0,379 \\
\hline & & & & e zu dd nicht signifikant & 0,1 \\
\hline \multirow[t]{7}{*}{$f$} & $-20258,73$ & 410416276,3 & $1,51816 \mathrm{E}+12$ & e zu yy nicht signifikant & 0,263 \\
\hline & 755342,08 & $5,70542 \mathrm{E}+11$ & $2,53026 \mathrm{E}+11$ & & \\
\hline & 26908,04 & 724042437,3 & 503017,2662 & f zu d sehr signifikant & $<0.001$ \\
\hline & 293548,92 & 86170966476 & & f zu e nicht signifikant & 0,356 \\
\hline & $-917146,88$ & $8,41158 \mathrm{E}+11$ & & f zu c sehr signifikant & $<0.001$ \\
\hline & $-138393,41$ & 19152736854 & & f zu i nicht signifikant & 0,448 \\
\hline & & & & f zu zz sehr signifikant & $<0.001$ \\
\hline \multirow[t]{6}{*}{$g$} & 1534828,65 & $2,3557 \mathrm{E}+12$ & $3,74541 \mathrm{E}+12$ & g zu h nicht signifikant & 0,808 \\
\hline & $-825024,62$ & $6,80666 \mathrm{E}+11$ & $7,49082 \mathrm{E}+11$ & g zu i nicht signifikant & 0,539 \\
\hline & $-519387,36$ & $2,69763 \mathrm{E}+11$ & 865495,351 & g zu a sehr signifikant & $<0.001$ \\
\hline & $-554094,98$ & $3,07021 \mathrm{E}+11$ & & g zu d sehr signifikant & $<0.001$ \\
\hline & 363678,33 & $1,32262 \mathrm{E}+11$ & & g zu ee nicht signifikant & 0,767 \\
\hline & & & & g zu xx nicht signifikant & 0,884 \\
\hline \multirow[t]{11}{*}{ h } & 278401,33 & 77507302773 & $1,69378 \mathrm{E}+12$ & h zu g nicht signifikant & 0,808 \\
\hline & $-632271,40$ & $3,99767 \mathrm{E}+11$ & $3,38755 \mathrm{E}+11$ & h zu i nicht signifikant & 0,634 \\
\hline & 1002877,99 & $1,00576 \mathrm{E}+12$ & 582026,6981 & h zu b sehr signifikant & $<0.001$ \\
\hline & $-332598,63$ & $1,10622 \mathrm{E}+11$ & & h zu e nicht signifikant & 0,379 \\
\hline & $-316409,31$ & $1,00115 \mathrm{E}+11$ & & h zu ff nicht signifikant & 0,085 \\
\hline & & & & h zu yy signifikant & 0,045 \\
\hline & $-550985,88$ & $3,03585 \mathrm{E}+11$ & $1,40394 \mathrm{E}+12$ & i zu g nicht signifikant & 0,539 \\
\hline & 223800,74 & 50086771225 & $2,80788 \mathrm{E}+11$ & i zu h nicht signifikant & 0,634 \\
\hline & $-276345,01$ & 76366564552 & 529894,1882 & i zu c sehr signifikant & $<0.001$ \\
\hline & 930961,45 & $8,66689 \mathrm{E}+11$ & & i zu f nicht signifikant & 0,448 \\
\hline & $-327431,30$ & $1,07211 \mathrm{E}+11$ & & i zu zz sehr signifikant & 0,004 \\
\hline
\end{tabular}




\section{Signifikanz nach t-Test}

\begin{tabular}{|c|c|c|c|c|c|}
\hline $\mathrm{aa}$ & 1774585,80 & $3,14915 \mathrm{E}+12$ & $1,05948 \mathrm{E}+13$ & aa zu bb signifikant & 0,021 \\
\hline & $-2600629,11$ & $6,76327 \mathrm{E}+12$ & $3,53159 \mathrm{E}+12$ & aa zu cc nicht signifikant & 0,192 \\
\hline & 826043,32 & $6,82348 \mathrm{E}+11$ & 1879252,874 & aa zu ee sehr signifikant & $<0.001$ \\
\hline & & & & aa zu xx sehr signifikant & 0,001 \\
\hline \multirow[t]{4}{*}{$\mathrm{bb}$} & 844179,77 & $7,12639 \mathrm{E}+11$ & $2,57569 \mathrm{E}+12$ & aa zu a nicht signifikant & 0,636 \\
\hline & 445875,24 & $1,98805 \mathrm{E}+11$ & $8,58562 \mathrm{E}+11$ & bb zu aa signifikant & 0,021 \\
\hline & $-1290055,02$ & $1,66424 \mathrm{E}+12$ & 926586,2378 & bb zu dd sehr signifikant & 0,004 \\
\hline & & & & bb zu ff sehr signifikant & $<0.001$ \\
\hline \multirow[t]{4}{*}{$\mathrm{CC}$} & 869511,47 & $7,5605 \mathrm{E}+11$ & $1,22183 \mathrm{E}+12$ & bb zu yy sehr signifikant & $<0.001$ \\
\hline & $-225283,97$ & 50752865637 & $4,07277 \mathrm{E}+11$ & bb zu b sehr signifikant & $<0.001$ \\
\hline & $-644227,51$ & $4,15029 \mathrm{E}+11$ & 638182,8756 & cc zu dd nicht signifikant & 0,92 \\
\hline & & & & cc zu aa nicht signifikant & 0,193 \\
\hline \multirow[t]{4}{*}{$\mathrm{dd}$} & 1347531,82 & $1,81584 \mathrm{E}+12$ & $6,88634 \mathrm{E}+12$ & cc zu ee sehr signifikant & $<0.001$ \\
\hline & $-2116432,85$ & $4,47929 E+12$ & $2,29545 \mathrm{E}+12$ & cc zu xx sehr signifikant & $<0.001$ \\
\hline & 768901,03 & $5,91209 \mathrm{E}+11$ & 1515073,024 & cc zu d sehr signifikant & 0,008 \\
\hline & & & & dd zu cc nicht signifikant & 0,92 \\
\hline \multirow[t]{6}{*}{ ee } & 442051,66 & $1,9541 \mathrm{E}+11$ & $1,01255 \mathrm{E}+12$ & dd zu bb sehr signifikant & 0,004 \\
\hline & 51018,12 & 2602848772 & $2,02511 \mathrm{E}+11$ & dd zu ff sehr signifikant & $<0.001$ \\
\hline & $-544455,25$ & $2,96432 \mathrm{E}+11$ & 450012,027 & dd zu yy sehr signifikant & 0,003 \\
\hline & 534018,34 & $2,85176 \mathrm{E}+11$ & & dd zu e nicht signifiaknt & 0,1 \\
\hline & $-482632,88$ & $2,32934 \mathrm{E}+11$ & & ee zu ff signifikant & 0,048 \\
\hline & & & & ee zu aa sehr signifikant & $<0.001$ \\
\hline \multirow[t]{6}{*}{$\mathrm{ff}$} & 235542,25 & 55480153419 & $3,7359 \mathrm{E}+11$ & ee zu cc sehr signifikant & $<0.001$ \\
\hline & 216351,75 & 46808081459 & 74717929183 & ee zu xx nicht signifikant & 0,518 \\
\hline & $-398690,81$ & $1,58954 \mathrm{E}+11$ & 273345,8051 & ee zu g nicht signifikant & 0,767 \\
\hline & 208910,35 & 43643536008 & & ff zu ee signifiaknt & 0,048 \\
\hline & $-262113,56$ & 68703516239 & & ff zu bb sehr signifikant & $<0.001$ \\
\hline & & & & ff zu dd sehr signifikant & $<0.001$ \\
\hline \multirow[t]{5}{*}{$x x$} & $-649584,50$ & $4,2196 \mathrm{E}+11$ & $8,43492 \mathrm{E}+11$ & ff zu yy nicht signifikant & 0,108 \\
\hline & $-211810,22$ & 44863570355 & $2,10873 \mathrm{E}+11$ & ff zu h nicht signifikant & 0,085 \\
\hline & 483932,76 & $2,34191 \mathrm{E}+11$ & 459209,1155 & & \\
\hline & 377461,97 & $1,42478 \mathrm{E}+11$ & & xx zu a sehr signifikant & 0,001 \\
\hline & & & & xx zu d sehr signifikant & $<0.001$ \\
\hline \multirow[t]{4}{*}{ yy } & $-37339,57$ & 1394243488 & 9129791212 & xx zu g nicht signifikant & 0,884 \\
\hline & 77992,74 & 6082867493 & 3043263737 & xx zu aa sehr signifikant & 0,001 \\
\hline & $-40653,17$ & 1652680231 & 55165,78412 & xx zu cc sehr signifikant & $<0.001$ \\
\hline & & & & xx zu ee nicht signifikant & 0,518 \\
\hline \multirow[t]{16}{*}{$\mathrm{ZZ}$} & 26873,32 & 722175193,5 & 1465525819395,45 & & \\
\hline & 10646,14 & 21292,28 & 91595363712 & yy zu b sehr signifikant & 0,002 \\
\hline & 1123382,37 & $1,26199 \mathrm{E}+12$ & 302647,2595 & yy zu e nicht signifikant & 0,263 \\
\hline & $-155942,88$ & 24318182602 & & yy zu h signifikant & 0,045 \\
\hline & $-32212,95$ & 1037674309 & & yy zu bb sehr signifikant & $<0.001$ \\
\hline & $-114494,44$ & 13108977363 & & yy zu dd sehr signifikant & 0,003 \\
\hline & $-157836,37$ & 24912320484 & & yy zu ff nicht signifikant & 0,108 \\
\hline & $-10532,52$ & 110934030,2 & & & \\
\hline & $-147346,45$ & 21710977064 & & zz zu c sehr signifikant & $<0.001$ \\
\hline & 23928,95 & 572594528,5 & & zz zu f sehr signifikant & $<0.001$ \\
\hline & 29202,31 & 852774763,3 & & zz zu i sehr signifikant & 0,004 \\
\hline & 21041,38 & 442739567,1 & & & \\
\hline & $-43147,84$ & 1861736312 & & & \\
\hline & $-217736,84$ & 47409332582 & & & \\
\hline & $-138087,30$ & 19068103112 & & & \\
\hline & $-217736,84$ & 47409332582 & & & \\
\hline
\end{tabular}




\section{LITERATURVERZEICHNIS}

Aaboe M, Pinholt EM, Hansen E (1994) :

Unicortical critical size defect of rabbit tibia is larger than $8 \mathrm{~mm}$

J Craniofac Surg $\underline{5}, 201-203$

Abendroth $\mathrm{K}$ :

Der Osteoblast: Funktion und hormonelle Regulation

in : Aktuelle Aspekte der Osteologie (A: Übersichtsreferate)

Herausgeber : Ittel TH, Sieberth HG, Matthiaß HH

Springer Verlag, Berlin, Heidelberg 1992, 3-9

Aoki H, Fujii M, Imamura T, Yagi K, Takehara K, Kato M, Miyazono K (2001) : Synergistic effects of different bone morphogenetic protein type I receptors on alkaline phosphatase induction

J Cell Sci 114, 1483-1489

Arosarena O und Collins W (2005a) :

Bone regeneration in the rat mandible with bone morphogenetic protein-2 : A comparison of two carriers

Otolaryngol Head Neck Surg 132, 592-597

Arosarena O und Collins W (2005b) :

Comparison of BMP-2 and-4 for rat mandibular bone regeneration at various doses

Othod Craniofac Res $\underline{8}, 267-276$

Aspenberg P, Jeppsson C, Wang JS, Boström M (1996) :

Transforming growth factor beta and bone morphogenetic protein 2 for bone ingrowth; a comparison using bone chambers in rats

Bone 1996; 19 , 499-503

Barnes GL, Kostenuik PJ, Gerstenfeld LC, Einhorn, TA (1999) :

Growth factor regulation of fracture repair

J Bone Miner Res 14, 1805-1815

Baumhoer D, Steinbrück I, Götz W :

Histologie mit Schemazeichnungen, 1. Auflage

Urban und Fischer Verlag, München 2000

Baylink D, Finkelman R, Mohan S (1993) :

Growth factors to stimulate bone formation

J Bone Miner Res $\underline{8}$, 565-572 
Beck L, Amento E, Xu Y, Deguzman L, Lee W, Nguyen T und Gillet N. (1993) : TGFbeta1 induces bone closure of skull defects - Temporal dynamics of bone formation in defects exposed to rhTGF-beta1

J Bone Miner Res $\underline{8}$, 753-761

Berens A, Schliephake H, Dilmaghani S, Schuster A (2000) :

Einfluss von Glaskeramiken auf die Knochenneubildung in Calvariadefekten Mund Kiefer GesichtsChir 4, 522-526

Boden SD (1999) :

Bioactive factors for tissue engineering

Clin Orthop $\underline{367}, 84-94$

Bolander ME (1992) :

Regulation of fracture repair by growth factors

Proc Soc Exp Biol Med 200, 165-170

Bosch C, Melsen B, Vargervik K (1998) :

Importance of the critical size defect in testing boneregeneration materials

J Craniofac Surg 9 , 310-316

Bostrom MP und Asnis P (1998) :

Transforming growth factor beta in fracture repair.

Clin Orthop $\underline{355}, 124-131$

Bostrom MP, Aspenberg P, Jeppson C, Salvati EA (1998) :

Enhancement of bone formation in the setting of repeated tissue deformation.

Clin Orthop $\underline{350}, 221-228$

Bostrom MP, Saleh KJ, Einhorn TA (1999) :

Osteoinductive growth factors in preclinical fracture and long bone defect models. Orthop Clin North Am $\underline{30}$, 647-658

Bouxsein ML, Turek TJ, Blake CA, D’Augusta D, Li X, Stevens M, Seeherman HJ, Wozney JM (2001) :

Recombinant human bone morphogenetic protein- 2 accelerates healing in a rabbit ulnar osteotomy model

J Bone Joint Surg Am 로, 1219-1230

Boyan BD, Lohmann CH, Somers A, Niederauer GG, Wozney JM, Dean DD, Carnes DL, Schwartz (1999) :

Potential of porous poly-D,L-lactide-co-glycolide particles as a carrier for recombinant human bone morphogenetic protein-2 during osteoinduction in vivo J Biomed Mater Res $\underline{46}, 51-59$

Boyne PJ (1996) :

Animal studies of application of rhBMP-2 in maxillofacial reconstruction Bone 19, 83-92 
Boyne PJ, Salina S, Nakamura A, Audia F, Shabahang S (2006) :

Bone regeneration using rhBMP-2 induction in hemimandibulectomy type defects of elderly sub-human primates

Cell Tissue Bank $\underline{7}, 1-10$

Burchardt H (1983) :

The biology of bone graft repair

Clin Orthop 174, 28-42

Busch O, Solheim E, Bang G und Tornes K (1996) :

Guided tissue regeneration and local delivery of insulinlike growth factor I by bioerodible polyorthoester membranes in rat calvarial defects

Int J Oral Maxillofac Implants 11, 498-505

Cárcamo J, Weis FM, Ventura F, Wieser R, Wrana JL, Attisano L, Massagué J (1994) :

Type I receptors specify growth-inhibitory and transcriptional responses to transforming growth factor $B$ and activin

Mol Cell Biol 14, 3810-3821

Centrella M, McCarthy E, Canalis E (1991) :

Current concepts review. Transforming growth factor-beta and remodeling of bone

J Bone Joint Surg Am 고, 1418-1228

Centrella M, Horowitz MC, Wozney JM, McCarthy (1994) :

Transforming growth factor-beta gene family members and bone

Endocr Rev 15, 27-39

Cleland JL, Duenas ET, Park A, Daughtery A, Kahn J, Kowalskis J,

Cuthbertson A (2001) :

Development of poly-(D,L-lactide--coglycolide) microsphere formulations

containing recombinant human vascular endothelial growth factor to promote local angiogenesis

J Control Rel 르, 13-24

Correia JJ, Chacko BM, Lam SS, Lin K (2001) :

Sedimentation studies reveal a direct role of phosphorylation in Smad3:Smad4 homo- and hetero-trimerization

Biochemistry $\underline{40}, 1473-1482$

Coulson RA (1983) :

Relationship between fluid flow and $\mathrm{O} 2$ demand in tissues in vivo and in vitro Perspect Biol Med 27, 121-126 
Chu TM, Warden SJ, Turner CH, Stewart RL (2007) :

Segmental bone regeneration using a load-bearing biodegradable carrier of bone morphogenetic protein-2

Biomaterials $\underline{28}, 459-467$

Cunningham NS, Paralkar V, Reddi AH (1992) :

Osteogenin and recombinant bone morphogenetic protein $2 \mathrm{~B}$ are chemotactic for human monocytes and stimulate transforming growth factor $B 1$ mRNA expression Proc Natl Acad Sci USA $\underline{89}$, 11740-11744

Dietsch P :

Biochemie des Osteoklasten

in : Aktuelle Aspekte der Osteologie (A: Übersichtsreferate)

Herausgeber : Ittel TH, Sieberth HG, Matthiaß HH

Springer Verlag, Berlin, Heidelberg 1992, 10-17

Ducy P und Karsenty G (2000) :

The family of bone morphogenetic proteins

Kidney Int 57, 2207-2214

Ebisawa T, Tada K, Kitajima I, Tojo K, Sampath T, Kawabata M, Miyazono K, Imamura T (1999) :

Characterization of bone morphogenetic protein- 6 signaling pathways in osteoblast differentiation

J Cell Sci 112, 3519-3527

Einhorn TA (1998) :

The cell and molecular biology of fracture healing

Clin Orthop $\underline{355}, 7-21$

Foitzik C und Merten HA :

Knochenersatz- und Knochenaufbaumaterialien in der Implantologie und bei der Behandlung von Knochendefekten

in : Innovationen für die Zahnheilkunde

Herausgeber : Heinenberg BJ

SpittaVerlag, Balingen 1999, 1-50

Friedländer GE, Perry CR, Cole JD, Cook SD, Cierny G, Muschler GF, Zych GA, Calhoun JH, LaForte AJ, Yin S (2001) :

Osteogenic Protein-1 (bone morphogentic protein-7) in the treatment of tibial nonunions

J Bone Joint Surg Am $\underline{83}, 151-158$

Gao TJ, Lindholm TS, Marttinen A, Puolakka T (1993) :

Bone inductive potential and dose-dependent response of bovine bone morphogenetic protein combined with type IV collagen carrier

Ann Chir Gynaecol 207, 77-84 
Geesink RG, Hoefnagels NH, Bulstra SK (1999) :

Osteogenic activity of OP-1 bone morphogenetic protein (BMP-7) in a human fibular defect

J Bone Joint Surg 1ㅗ, 710-718

Gordh M, Alberius P, Johnell O, Lindberg L, Linder A (1999) :

Effects of rhBMP-2 and osteopromotive membranes on experimental bone grafting

Plast Reconstr Surg 103, 1909-1918

Grob D :

Autologous bone grafts: problems at the donator site

in : Bone Transplantation

Herausgeber : Aebi M, Regazzoni P

Springer Verlag: Berlin, Heidelberg, New York 1989, 245-260

Gürtler L (1994) :

Blood-borne viral infections

Blood Coagul Fibrinolysis 5, 5-10

Hanada K, Solchaga LA, Caplan AI, Hering TM, Goldberg VM, Yoo JU, Johnstone B (2001) :

BMP-2 induction and TGF-beta 1 modulation of rat periosteal cell chondrogenesis

J Cell Biochem $\underline{8}, 284-294$

Harris LD, Kim BS, Mooney DJ (1998) :

Open pore biodegradable matrices formed with gas foaming

J Biomed Mater Res $\underline{42}$, 396-402

Hayashi H, Abdollah S, Qiu Y, Cai J, Xu YY, Grinnell BW, Richardson MA, Topper JN, Gimbrone MA, Wrana JL (1997) :

The MAD-related protein Smad7 associates with the TGFß receptor and functions as an antagonist of TGFß signaling

Cell $\underline{\text { 89, }}$ 1165-1173

Heldin CH, Miyazono K, ten Dijke P (1997) :

TGF-beta signalling from cell membrane to nucleus through SMAD proteins

Nature $\underline{390}, 465-471$

Hierholzer G und Zilch $\mathrm{H}$ :

Transplantatlager und Implantatlager bei verschiedenen Operationsverfahren Springer Verlag, Berlin 1980

Higuchi T, Kinoshita A, Takahashi K, Oda S, Ishikawa I (1999) :

Bone regeneration by recombinant human bone morphogenetic protein- 2 in rat mandibular defects. An experimental model of defect filling

J Periodontol 70, 1026-1031 
Hile DD, Amirpour ML, Akgerman A, Pishko MV (2000) :

Active growth factor delivery from poly(D, L-lactide-co-glycolide) foams prepared in supercritical $\mathrm{CO}_{2}$

J Control Rel $\underline{66}, 177-185$

Hock JM, Centrella M, Canalis E (1988) :

Insulin-like growth factor I has independent effects on bone matrix formation and cell replication

Endocrinology 122, 254-260

Hogan BL (1996a) :

Bone morphogenetic proteins in development

Curr Opin Genet Dev $\underline{6}, 432-438$

Hogan BL (1996b) :

Bone morphogenetic proteins: multifunctional regulators of vertebrate development Genes Dev 10, 1580-1594

Hollinger JO und Kleinschmidt AO :

Animal models in bone research

in : Bone Grafts and Bone Substitution

Herausgeber : Habal MB, Reddi AH

W. B. Saunders, New York, 1992, 133-146

Hollinger JO, Schmitt JM, Buck DC, Shannon R, Joh SP, Zegula HD, Wozney J (1998) :

Recombinant human bone morphogenetic protein-2 and collagen for bone regeneration

J Biomed Mater Res 43, 356-364

Horisaka Y, Okamoto Y, Matsumoto N, Yoshimura Y, Nishida M, Kawada J, Yamashita K, Takagi T (1994) :

Histological changes of implanted collagen material during bone induction

J Biomed Mater Res 2ㅇ, 97-103

Horn F, Lindenmeier G, Moc I, Grillhösl C, Berghold S, Schneider N,

Münster B :

Biochemie des Menschen, 2. Auflage

Thieme Verlag, Stuttgart 2003

Howdle SM, Watson MS, Whitaker MJ, Propov VK, Davies MC, Mandel FS, Wang DJ, Sjakesheff KM (2001) :

Supercritical fluid mixing: Preparation of thermally sensitive polymer composites containing bioactive materials

Chem Commun 2001, 109-110 
Hu Y, Hollinger JO, Marra KG (2001) :

Controlled release from coated polymer microparticles embedded in tissueengineered scaffolds

J Drug Target $\underline{9}, 431-438$

Hyun SJ, Han, DK, Choi, SH, Chai JK, Cho KS, Kim CK, Kim CS (2005) :

Effect of recombinant human bone morphogenetic protein-2, -4 , and -7 on bone formation in rat calvarial defects

J Periodontol 76, 1667-1674

Imamura T, Takase M, Nishihara A, Oeda E, Hanai JI, Kawabata M, Miyazono K (1997):

Smad6 inhibits signalling by the TGF- $\beta$ superfamily

Nature $\underline{389}, 622-626$

Itoh T, Mochizuki M, Nishimura R, Matsunaga S, Kadosawa T, Kokubo S, Yokota S, Sasaki N (1998) :

Repair of ulnar segmental defect by recombinant human bone morphogenetic protein-2 in dogs

J Vet Med Sci 60, 451-458

Johnson EE und Urist MR (2000) :

Human bone morphogenetic protein allografting for reconstruction of femoral nonunion

Clin Orthop $\underline{371}, 61-74$

Joyce M, Jingushi S, Bolander ME (1990a) :

Transforming growth factor-beta in the regulation of fracture repair Orthop Clin North Am 21, 199-209

Joyce M, Roberts AB, Sporn M, Bolander ME (1990b) :

Transforming growth factor-beta and the initiation of chondrogenesis and osteogenesis in the rat femur

J Cell Biol 110, 2195-2207

Kanematsu A, Yamamoto S, Ozeki M, Noguchi T, Kanatani I, Ogawa O, Tabata Y (2004) :

Collagenous matrices as release carriers of exogenous growth factors Biomaterials 25, 4513-4520

Katoh T, Sato K, Kawamura M, Iwata H, Miura T (1993) :

Osteogenesis in sintered bone combined with bovine bone morphogenetic protein Clin Orthop 287, 266-275

Kawabata M, Inoue H, Hanyu A, Imamura T, Miyazono K (1998) : Smad proteins exist as monomers in vivo and undergo homo- and heterooligomerization upon activation by serine/threonine kinase receptors EMBO J 17, 4056-4065 
Kawamura M und Urist MR (1988) :

Induction of callus formation by implants of bone morphogenetic protein and associated bone matrix noncollagenous proteins

Clin Orthop 236, 240-248

Kim CS, Kim JI, Kim J,Choi, SH, Chai JK, Kim CK, Cho, KS (2005) :

Ectopic bone formation associated with recombinant human bone morphogenetic proteins-2 using absorbable collagen sponge and beta tricalcium phosphate as carriers

Biomaterials 26, 2501-2507

King TW und Patrick CW jr. (2000) :

Development and in vitro characterization of vascular endothelial growth factor (VEGF)-loaded poly(DL-lactic-co-glycolic acid)/poly(ethylene glycol) microspheres using a solid encapsulation/single emulsion/solvent extraction technique

J Biomed Mater Res, 토, 383-390

Kirker-Head CA (1995) :

Recombinant bone morphogenetic proteins: novel substances for enhancing bone healing

Vet Surg 24, 408-419

Kloss FR, Schlegel KA, Felszeghy E, Wiltfang J (2004) :

Anwendung eines osteoinduktiven Proteinkomplexes zur Regeneration knöcherner Defekte

Mund Kiefer GesichtsChir $\underline{8}, 12-17$

Koenig BB, Cook JS, Wolsing DH, Ting J, Tiesman JP, Correa PE, Olson CA, Pecquet AL, Ventura F, Grant RA, et al. (1994) :

Characterization and cloning of a receptor for BMP-2 and BMP-4 from NIH 3T3 cells

Mol Cell Biol 14, 5961-5974

Korchynsky O und ten Dijke P :

Bone morphogenetic protein receptors and their nuclear effectors in bone formation

in : Bone Morphogenetic Proteins - From Laboraty to clinical Practice

Herausgeber : Vukicevic S, Sampath KT

Birkhäuser Verlag, Basel 2002, 31-60

Kuboki Y, Saito T, Murata M, Takita H, Mizuno M, Inoue M, Nagai N, Poole AR, (1995) :

Two distinctive BMP-carriers induce zonal chondrogenesis and membranous ossification, respectively: geometrical factors of matrices for cell-differentiation Con Tis Res $\underline{32}, 219-226$ 
Kuboki Y, Takita H, Kobayashi D, Tsuruga E, Inoue M, Murata M, Nagai N, Dohi Y, Ohgushi H (1998) :

BMP-induced osteogenesis on the surface of hydroxyapatite with geometrically feasible and nonfeasible structures: topology of osteogenesis

J Biomed Mater Res 39, 190-199

Kulkarni RK, Pani KC, Neuman C, Leonard F (1966) :

Polylactic acid for surgical implants

Arch Surg 93, 839-843

Kusumoto K, Bessho K, Fujimura K, Ogawa Y, Iizuka T (1997) :

Intramuscular osteoinduction and bone marrow formation by the implantation of rhBMP-2 with atelopeptide type I collagen

Br J Oral Maxillofac Surg 포, 433-437

Kübler NR (1997) :

Osteoinduktion und -reparation

Mund Kiefer GesichtsChir 1, 2-25

Kübler NR (1999) :

Knochenbildende Proteine- Neue Therapiekonzepte in der Knochenchirurgie Zbay Zahnärzte in Bayern $\underline{10}, 1-5$

Lagna G, Hata A, Hemmati-Brivanlou A, Massagué J (1996) :

Partnership between DPC 4 and SMAD proteins in TGF- $\beta$ signalling pathways

Nature $\underline{383} ; 832-836$

Lane JM, Yasko AW, Tomin E, Cole BJ, Waller S, Browne M, Turek T, Gross J (1999) :

Bone marrow and recombinant human bone morphogenetic protein- 2 in osseous repair

Clin Orthop $\underline{361}, 216-227$

Laurencin C und Lane JM :

Poly/(lactic acid) and Poly(glycolic acid):Orthopaedic Surgery Applications

in : Bone Formation and Repair

Herausgeber : Brighton CT, Friedlaender G, Lane JM

American Academy of Orthopaedic Surgeons, Rosemont 1994, 325-339

Lee DD, Tofighi A, Aiolova M, Chakravarthy P, Catalan A, Majahad A, Knaack D (1999) :

$\alpha$-BSM®: A Biomimetic Bone Substitute and Drug Delivery Vehicle

Clin Orthop $\underline{367}, 396-405$

Levander G (1938) :

A study of bone regeneration

Surg Gynecol Obstet 67, 705-714 
Li RH und Wozney JM (2001) :

Delivering on the promise of bone morphogenetic proteins

Trends Biotechnol 19, 255-265

Lind M, Eriksen EF, Bunger C (1996) :

Bone morphogenetic protein-2 but not bone morphogenetic protein- 4 and -6 stimulates chemotactic migration of human osteoblasts, human marrow osteoblasts, and U2-OS cells

Bone $\underline{18}, 53-57$

Lindholm TC, Lindholm TS, Alitalo I, Urist MR (1988) :

Bovine bone morphogenetic protein (bBMP) induced repair of skull trepine defects in sheep

Clin Orthop 227, 265-268

Littenberg B, Weinstein LP, McCarren M, Mead T, Swiontkowski MF, Rudicel SA, Heck D (1998) :

Closed fractures of the tibial shaft. A meta-analysis of three methods oftreatment J Bone Joint Surg Am $\underline{80}, 174-183$

Liu F, Ventura F, Doody J, Massagué J (1995) :

Human type II receptor for bone morphogenetic proteins (BMPs): extension of the two-kinase receptor model to the BMPs

Mol Cell Biol 15, 3479-3486

Lord F, Gebhardt M, Tomford WW, Mankin H (1988) :

Infection in bone allografts

J Bone Joint Surg $\underline{70}$, 369-376

Martin RB (2000) :

Toward a unifying theoriy of bone remodelling

Bone 26 ,1-6

Martin TJ (1988) :

Cell biology in bone

Baillieres Clin Endocrinol Metab 2, 1-29

Martinovic S, Borovecki F, Sampath KT, Vukicevic S :

Biology of bone morphogenetic proteins

in : Bone Morphogenetic Proteins - From Laboraty to clinical Practice

Herausgeber : Vukicevic S, Sampath KT

Birkhäuser Verlag, Basel 2002, 87-119

Marukawa E, Asahina I, Oda M, Seto I, Alam MI, Enomoto S (2001) :

Bone regeneration using recombinant human bone morphogenetic protein-2

(rhBMP-2) in alveolar defects of primate mandibles

Br J Oral Maxillofac Surg 39, 452-459 
Massagué J (1998) :

TGF-beta signal transduction

Annu Rev Biochem 67, 753-791

Massagué J und Wotton D (2000) :

Transcriptional control by the TGF- $3 /$ Smad signaling system

EMBO J $\underline{19}, 1745-1754$

McKibbin B (1978) :

The biology of fracture healing in long bones

J Bone Joint Surg Br $\underline{60}, 150-162$

Miki T, Harada K, Imai Y, Enomoto S (1994) :

Effect of freeze-dried poly-L-lactic acid discs mixed with bone morphogenetic protein on the healing of rat skull defects

J Oral Maxillofac Surg 2, 387-391

Mohan S und Baylink DJ (1991) :

Bone growth factors

Clin Orthop 263, 30-48

Moll KJ und Moll M :

Anatomie, Kurzlehrbuch, 17. Auflage

Urban und Fischer Verlag, München 2003

Mooney DJ, Baldwin DF, Suh NP, Vacanti JP, Langer R (1996) :

Novel approach to fabricate porous sponges of poly(D,L-lactic-co-glycoloic acid) without the use of organic solvents

Biomaterials 17, 1417-1422

Murata M, Inoue M, Arisue M, Kuboki Y, Nagai N (1998) :

Carrier-dependency of cellular differentiation induced by bone morphogenetic protein in ectopic sites

Int J Oral Maxillofac Surg 27, 391-396

Nagao H, Tachikawa N, Miki T, Oda M, Mori M, Takahashi K, Enomoto S (2002) :

Effect of recombinant human bone morphogenetic protein- 2 on bone formation in alveolar ridge defects in dogs

Int J Oral Maxillofac Surg $\underline{31}$, 66-72

Nakajima F, Yamazaki M, Ogasawara A (1998) :

Recombinant human basic fibroblast growth factor accelerates fracture healing by enhancing callus remodeling in experimental dog tibial fracture

Trans Orthop Res Soc 23, 596-605 
Nakao A, Afrakhte M, Moren A, Nakayama T, Christian JL, Heuchel R, Itoh S, Kawabata M, Heldin NE, Heldin CH, ten Dijke P (1997) :

Identification of Smad7, a TGFbeta-inducible antagonist of TGF-beta signalling Nature $\underline{389}, 631-635$

Nickel J, Dreyer M, Sebald W :

Deciphering the binding code of BMP-receptor interaction

in : Bone Morphogenetic Proteins - From Laboraty to clinical Practice

Herausgeber : Vukicevic S, Sampath KT

Birkhäuser Verlag, Basel 2002, 61-86

Nishimura R, Kato Y, Chen D, Harris SE, Mundy GR, Yoneda T (1998) :

Smad5 and DPC4 are the key molecules in mediating BMP-2 induced osteoblastic differentiation of the pluripotent mesenchymal precursor cell line $\mathrm{C} 2 \mathrm{C} 12$ J Biol Chem 273, 1872-1879

Nkenke E, Schultze-Mosgau S, Kloss F, Neukam FW, Radespiel-Troger M (2001) :

Morbidity of harvesting of chin grafts : aprospective study

Clin Oral Implants Res $\underline{12}$, 495-502

Nohno T, Ishikawa T, Saito T, Hosokawa K, Noji S, Wolsing DH,

Rosenbaum JS (1995) :

Identification of a human type II receptor for bone morphogenetic protein-4 that forms differential heteromeric complexes with bone morphogenetic protein type I receptors

Biol Chem 270, 22522-22526

Oka K, Oka S, Sasaki T, Ito Y, Bringas P jr., Nonaka K, Chai Y (2007) :

The role of TGF-beta signaling in regulating chondrogenesis and osteogenesis during mandibular development

Dev Biol 303, 391-404

Oliveira JM, Rofrigues MT, Silva SS, Malafaya PB, Gomes ME, Viegas CA, Dias IR, Azevedo JT, Mano JF, Reis RL (2006) :

Novel Hydroxylapatite/chitosan bilayered scaffold for osteochondral tissueengineering applications: scaffold design and its performance when seeded with goat bone marrow stromal cells

Biomaterials 27, 6123-6137

Ollier L :

Traité experimental et clinique de la regénération des os et de la production artificielle du tissu osseux

Victor Mason et Fils, Paris 1867

Owen M (1970) :

The origin of bone cells

Int Rev Cytol 28, 213-238 
Ozkaynak E, Schnegelsberg PN, Oppermann H (1991) :

Murine osteogenic protein (OP-1): high levels of mRNA in kidney

Biochem Biophys Res Commun 179, 116-123

Pang EK, Im SU, Kim CS, Choi SH, Cai JK, Kim CK, Han SB, Cho KS (2004) : Effect of recombinant human Bone morphogenetic protein-4 dose on Bone formation in a rat calvarial defect model

J Periodontol $\underline{75}$, 1364-1370

Paralkar VM, Grasser WA, Baumann AP, Castleberry TA, Owen TA, Vukicevic S :

Prostate-derived factor and growth and differentiation factor-8:

newly discovered members of the TGF- $\beta$ superfamily

in: Bone Morphogenetic Proteins - From Laboraty to clinical Practice

Herausgeber : Vukicevic S, Sampath KT

Birkhäuser Verlag, Basel 2002, 19-30

Piek, Heldin CH, ten Dijke P (1999) :

Specificity, diversity, and regulation in TGF-beta superfamily signaling

FASEB J $\underline{13}, 2105-2124$

Prisell PT, Edwall D, Lindblad JB, Levinovitz A, Norstedt G (1993) :

Expression of insulin-like growth factors during bone induction in rat

Calcif Tissue Int 53, 201-205

Raghoebar GM, Batenburg RH, Vissink A, Reintsema H (1996) :

Augmentation of localized defects of the anterior maxillary ridge with autogenous bone before imsertion of implants

J Oral Maxillofac Surg 54, 1180-1185

Rakosi T und Jonas I :

Kieferorthopädie-Diagnostik

in : Farbatlanten der Zahnmedizin,

Herausgeber : Rateitschak $\mathrm{H}$

Georg Thieme Verlag, Stuttgart, New York 1989, 6-34

Ramoshebi LN, Matsaba T, Teare J, Renton L, Patton J, Ripamonti U (2002) : Tissue engineering: TGF- $\beta$ superfamily members and delivery systems in bone regeneration

Exp Rev Mol Med 4, 1-11

Ratner BD, Hoffman AS, Schoen FJ, Lemons JE

Biomaterials Science : An Introduction to Materials in Medicine

Academic Press, Amsterdam 2004

Reddi AH (1994) :

Bone and cartilage differentiation

Curr Opin Cell Biol 4, 737-744 
Reddi AH (1998) :

Initiation of fracture repair by bone morphogenetic proteins

Clin Orthop $\underline{355}, 66-72$

Reddi AH (2000a) :

Bone morphogenentic proteins and skeletal development: the kidney-bone connection Pediatr Nephrol 14, 598-601

Reddi AH (2000b) :

Morphogenetic messages are in the extracellular matrix: biotechnology from bench to bedside

Biochem Soc Trans $\underline{28}, 345-349$

Reddi AH (2000c) :

Morphogenesis and tissue engineering of bone and cartilage: inductive signals, stem cells, and biomimetic biomaterials

Tissue Eng $\underline{6}$, 351-359

Reddi AH (2001) :

Bone Morphogenic Proteins: From Basic Science to Clinical Applications

J Bone Joint Surg Am $\underline{\text { 83, 1-6 }}$

Riedel GE und Valentin-Opran A (1999) :

Clinical evaluation of rhBMP-2/ACS in orthopedic trauma: a progress report

Orthopedics $\underline{22}$, 663-665

Rinderknecht E und Humbel RE (1978) :

Primary structure of human insulin-like growth factor II

FEBS Lett $\underline{89}$, 283-286

Ripamonti U und Reddi AH (1992) :

The critical role of geometry of porous hydroxyapatite delivery system in induction of bone by osteogenin, a bone morphogenetic protein

Matrix 12, 202-212

Robey PG, Young MF, Flanders KC (1987) :

Osteoblasts synthesize and respond to transforming growth factor-type beta (TGF-beta) in vitro

J Cell Biol 105, 457-463

Roldan JC, Jepsen S, Miller J, Freitag S, Rueger DC, Acil Y, Terheyden H (2004) :

Bone formation in the presence of platelet-rich plasma vs. bone morphogenetic protein-7

Bone $\underline{34}, 80-90$ 
Rosenzweig BL, Imamura T, Okadome T, Cox GN, Yamashita H, ten Dijke P, Heldin CH, Miyazono K (1995) :

Cloning and characterization of a human type II rezeptor for bone morphogenetic proteins

Proc Natl Acad Sci USA 92; 7632-7636

Rosier RN, O'Keefe RJ, Hicks DG (1998) :

The potential role of transforming growth factor beta in fracture healing

Clin Orthop $\underline{355}, 294-300$

Rueger DC :

Biochemistry of bone morphogenetic proteins

in : Bone Morphogenetic Proteins - From Laboraty to clinical Practice

Herausgeber : Vukicevic S, Sampath KT

Birkhäuser Verlag, Basel 2002, 1-18

Rueger JM :

Allogener Knochen und Knochenersatzmittel

in : Unfallchirurgie

Herausgeber : Rüter A, Trentz O, Wagner M

Urban \& Schwarzenberg: München, Wien, Baltimore 1995, 51- 56

Rueger JM (1998) :

Knochenersatzmittel - heutiger Stand und Ausblick

Der Orthopäde 27, 72-79

Ruppert R, Hoffmann E, Sebald W (1996) :

Human bone morphogenetic protein 2 contains a heparin-binding site which modifies its biological activity

Eur J Biochem 237, 295-302

Sakou T (1998) :

Bone morphogenetic proteins: from basic studies to clinical approaches

Bone 22, 591-603

Sampath TK und Reddi AH (1983) :

Homology of bone-inductive proteins from human, monkey, bovine, and rat extracellular matrix

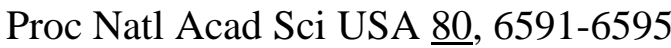

Sampath TK, Maliakal JC, Hauschka PV, Jones WK, Sasak H, Tucker RF, White KH, Coughlin JE, Tucker MM, Pang RH (1992) :

Recombinant human osteogenetic protein-1 (hOP-1) induces new bone formation in vivo with a specific activity comparable with natural bovine osteogenic protein and stimulates osteoblast proliferation and differentiation in vitro

J Biol Chem 267, 20352-20362 
Sandberg M, Autio-Harmainen H, Vuorio E (1988) :

Localization of the expression of types I, III, and IV collagen, TGF-beta 1 and cfos genes in developing human calvarial bones

Dev Biol 130, 324-334

Sasano Y, Ohtani E, Narita K, Murata M, Saito T, Shigenobu K, Takita H, Mizuno M, Kuboki Y (1993) :

BMPs induce direct bone formation in ectopic sites independent of the endochondral ossification in vivo

Anat Rec 236, 373-380

Sato K und Urist MR (1985) :

Induced regeneration of calvaria by bone morphogenetic protein (BMP) in dogs Clin Orthop 197, 301-311

Savage C, Das P, Finelli AL, Townsend SR, Sun CY, Baird SE, Padgett RW (1996) :

Caenorhabditis elegans genes sma-2, sma-3, and sma-4 define a conserved family of transforming growth factor $B$ pathway components

Proc Natl Acad Sci USA 93, 790-794

Schenk C, Schwarz A, Kaupe AJ, Wiltfang J, Neukam FW (2000) :

Erfahrungen mit autologen Beckenkammtransplantationen im Ober-und Unterkiefer -Vergleich der anterioren und posterioren Entnahmetechnik Dtsch Zahnärztl Z ⒌ 355-358

Schiller C, Rasche C, Wehmöller M, Beckmann F, Eufinger H, Epple M, Weihe S (2004) :

Geometrically structured implants for cranial reconstruction made of biodegradable polyesters and calcium phosphate/calcium carbonate

Biomaterials 25, 1239-1247

Schlegel KA, Donath K, Weida S (1998) :

Histological findings in guided bone regeneration around titanium implants with autogenous bonechips using a new resorbable membrane

Int J Biomater Med Implants $\underline{8}, 211-224$

Schliephake H (2002) :

Bone growth factors in maxillofacial skeletal reconstruction Int J Oral Maxillofac Surg $\underline{31}$, 469-484

Schliephake H, Weich HA, Schulz J, Gruber R (2007) :

In vitro characterization of a slow release system of polylactic acid and rhBMP2 Biomed Mater Res 83, 455-462 
Schratt HE und Spyra JL (1997) :

Experimentelle Untersuchungen zur Einheilung und Antigenität von sterilisierten Knochentransplantaten

Der Chirurg $\underline{68}, 77-83$

Schwartz Z, Somers A, Mellonig JT, Carnes DL jr., Wozney JM, Dean DD, Cochran DL, Boyan BD (1998) :

Addition of human recombinant bone morphogenetic protein-2 to inactive commercial human demineralized freeze-dried bone allograft makes an effective composite bone inductive implant material

J Periodontol $\underline{69}, 1337-1345$

Schwenzer N und Ehrenfeld M :

Plastische und wiederherstellende Mund-, Kiefer-,Gesichts-Chirurgie

in : Zahn-, Mund-, Kieferheilkunde: Lehrbuch zur Aus- und Weiterbildung -

Band 2: Spezielle Chirurgie

Herausgeber : Schwenzer N, Ehrenfeld M,

Georg Thieme Verlag, Stuttgart, New York 2002, 379-416

Seeherman HJ, Azari K, Bidic S, Rogers L, Li XJ, Hollinger JO, Wozney JM (2006) :

RhBMP-2 delivered in a calcium phosphate cement accelerates bridging of critical size dSeehermanefects in rabbit radii

J Bone Joint Surg Am $\underline{88}, 1553-1565$

Sekelsky JJ, Newfeld SJ, Raftery LA, Chartoff EH, Gelbart WM (1995) :

Genetic characterization and cloning of mothers against dpp, a gene required for decapentaplegic function in Drosophila melanogaster

Genetics $\underline{139}, 1347-1358$

Shi Y, Hata A, Lo RS, Massagué J, Pavletich NP (1997) :

A structural basis for mutational inactivation of the tumor supressor $\operatorname{Smad} 4$

Nature $\underline{388}, 87-93$

Simmonds RJ, Holmberg SD, Hurwitz RL (1992) :

Transmission of human immunodefiency virus type 1 from a seronegative organ and tissue donor

N Engl J Med 326, 726-732

Smith LG und Karagianes MT (1974) :

Histological preparation of bone to study ingrowth into implanted materials

Calcif Tissue Res $\underline{14}$, 333-337

Stützle H, Hallfeldt K, Mandelkow H, Kessler S, Schweiberer L (1998) :

Knochenneubildung durch Knochenersatzmaterialien

Orthopäde 27, 118-125 
ten Dijke P, Yamashita H, Sampath TK, Reddi AH, Estevez M, Riddle DL, Ichijo H, Heldin CH, Miyazono K (1994) :

Identification of type I receptors for osteogenic protein-1 and bone morphogenetic protein-4

J Biol Chem 269, 16985-16988

ten Dijke P, Miyazono K, Heldin CH (2000) :

Signaling inputs converge on nuclear effectors in TGF- $\beta$ signaling

Trends Biochem Sci $\underline{25}$, 64-70

Thaller SR, Dart A, Tesluk H (1993) :

The effects of insulin-like growth factor-1 on criticalsize calvarial defects in Sprague-Dawley rats

Ann Plast Surg $\underline{31}$, 429-433

Trippel SB, Coutis RD, Einhorn TA, Mundy GR, Rosenfeld RG (1996) :

Growth factors as therapeutic agents

J Bone Joint Surg Am 모, 1272-1286

Tschakaloff A, von Oepen R, Seibt S, Vieting M (1996) :

Das Begasungsverfahren zur Beladung resorbierbarer Polymere mit thermolabilen

Substanzen

Dtsch Z MundKieferGesichtsChir 20, 47-50

Tschakaloff A, Schliephake H, Dard M (2000) :

Pilotstudie zur kontrollierten Freisetzung von Wachstumsfaktoren aus

Polylaktidkörpern

Mund Kiefer GesichtsChir 4, 474-478

Tsuruga E, Takita H, Itoh H, Wakisaka Y, Kuboki Y (1997) :

Pore size of porous hydroxyapatite as the cell-substratum controls BMP-induced osteogenesis

J Biochem (Tokyo) 121, 317-324

Uludag H, D’Augusta D, Palmer R, Timony G, Riedel R, Wozney JM (2000) :

Implantation of recombinant human bone morphogenetic proteins with biomaterial carriers: a correlation between protein pharmacokinetics and osteoinduction in the rat ectopic model

J Biomed Mater Res 50, 227-238

Urist MR (1965) :

Bone: Formation by autoinduction

Science $\underline{150}$, 893-899

Urist MR, Silverman BF, Büring K, Dubuc FL, Rosenberg JM (1967) :

The bone induction principle

Clin Orthop 53, 243-283 
Urist MR, Mikulski A, Lietze A (1979) :

Solubilized and insolubilized bone morphogenetic protein

Proc Natl Acad Sci $\underline{76}$, 1828-1832

Valentin-Opran A, Wozney J, Csimma C, Lilly L, Riedel GE (2002) :

Clinical evaluation of recombinant human bone morphogenetic protein-2

Clin Orthop Rel Res $\underline{395}, 110-120$

van den Eijnden-van Raaij AJ, Koornneef I, van Zoelen EJ (1988) :

A new method for high yield purification of type beta transforming growth factor from human platelets

Biochem Biophys Res Commun 157, 16-23

Vehof JW, Mahmood J, Takita H, van`t Hof MA, Kuboki Y, Spauwen PH, Jansen JA (2001):

Ectopic bone formation in titanium mesh loaded with bone morphogenetic protein and coated with calcium phosphate

Plast Reconstr Surg 108, 434-443

Wang EA, Rosen V, Cordes P, Hewick RM, Kritz MJ, Luxenburg DP, Sibley BS, Wozney JM (1988) :

Purification and characterizationof other distinct bone-inducing factors

Proc Natl Acad Sci USA 모, 9484-9488

Wang EA, Rosen V, D'Alessandro JS, Bauduy M, Cordes P, Harada T, Israel DI, Hewick RM, Kerns KM, LaPan P, et al. (1990) :

Recombinant human bone morphogenetic protein induces bone formation

Proc Natl Acad Sci 87, 2220-2224

Wang JS und Aspenberg P (1996) :

Basic fibroblast growth factor promotes bone ingrowth in porous hydroxyapatite Clin Orthop $\underline{333}, 252-260$

Winn SR, Uludag H, Hollinger JO (1998) :

Sustained release emphasizing recombinant human bone morphogenetic protein-2 Adv Drug Deliv Rev 31, 303-318

Winn SR, Uludag H, Hollinger JO (1999) :

Carrier systems for bone morphogenetic proteins

Clin Orthop $\underline{367}$, 95-106

Wozney JM und Rosen (1998) :

Bone morphogenetic protein and bone morphogenetic protein gene family in bone formation and repair

Clin Orthop $\underline{346}$, 26-37 
Wozney JM, Rosen V, Celeste AJ, Mitsock LM, Whitters MJ, Kritz RW, Herwick RM, Wang EA (1988) :

Novel regulators of bone formation: molecular clones and activities

Science 242, 1528-1534

Würzler KK, Kübler NR, Reuther JF (2000) :

Einfluss des Periosts auf die induzierte Knochenneubildung durch autolysierten, antigenextrahierten, allogenen Knochen

Mund Kiefer Gesichts Chir 4, 459-464

Yamashita H, ten Dijke P, Huylebroeck D, Sampath TK, Andries M, Smith JC, Heldin CH, Miyazono K (1995) :

Osteogenic protein-1 binds to activin type II receptors and induces certain activinlike effects

J Cell Biol 130, 217-226

Yamashita H, ten Dijke P, Heldin CH, Miyazono K (1996) :

Bone Morphogenetic Protein Receptors

Bone $\underline{19}, 569-574$

Zegzula HD, Buck DC, Brekke J, Wozney JM, Hollinger JO (1997) :

Bone Formation with Use of rhBMP-2 (Recombinant Human Bone

Morphogenetic Protein-2)

J Bone Joint Surg Am $\underline{79}, 1778-1790$ 


\section{Lebenslauf}

Geboren wurde ich, Sarah Frase, geborene Lunk, am 22.10.1981 in Göttingen.

Ich wuchs in Bovenden auf und besuchte dort von 1988-1992 die örtliche

Grundschule und im Anschluss daran von 1992-1994 die Orientierungsstufe

Bovenden.

Ab Sommer 1994 besuchte ich das Hainberg-Gymnasium in Göttingen, wo ich im Juni 2001 mein Abitur machte.

Im Wintersemester 2001/2002 begann ich das Studium der Rechtswissenschaften an der Georg-August-Universität Göttingen, wechselte jedoch zum

Wintersemester 2002/2003 in den Studiengang Zahnmedizin. Im September 2003 bestand ich die naturwissenschaftliche Vorprüfung und absolvierte im März 2005 die zahnärztliche Vorprüfung.

Am 09.06.2006 heiratete ich meinen Mann Holger Frase.

Im November 2007 schloss ich das Studium der Zahnheilkunde mit erfolgreicher Examensprüfung ab und erhielt die Approbation als Zahnärztin.

Seit Januar 2008 arbeitete ich in der Zahnarztpraxis Hans-Volker Kühnert in Adelebsen, erhielt jedoch durch meine Schwangerschaft ab August 2008 Beschäftigungsverbot.

Am 16.04.2006 kam unsere Tochter Alena auf die Welt. Seitdem befinde ich mich - bis voraussichtlich Mai 2010 - in Elternzeit.

16.Oktober 2009

Sarah Frase 